Supporting Information

\title{
Beetleane A and Epicoane A: Two Carbon Skeletons Produced by Epicoccum nigrum
}

Peng-Ran Cao ${ }^{[a]}$, Yi-Lei Zheng ${ }^{[a]}$, Yong-Qin Zhao ${ }^{[a]}$, Xiao-Bing Wang ${ }^{[a]}$, Hao Zhang ${ }^{[a]}$, Mei-Hui Zhang ${ }^{[a]}$, Ting Yang ${ }^{[a]}$, Yu-Cheng $\mathrm{Gu}^{[\mathrm{b}]}$, Ming-Hua Yang*[a] and Ling-Yi Kong*[a]

[a] Jiangsu Key Laboratory of Bioactive Natural Product Research and State Key Laboratory of Natural Medicines, China Pharmaceutical University, 24 Tong Jia Xiang, Nanjing 210009, People's Republic of China.

[b] Syngenta, Jealott's Hill International Research Centre, Bracknell, Berkshire RG42 6EY, United Kingdom 


\section{Table of Contents}

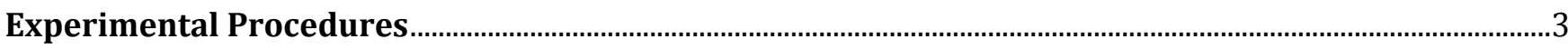

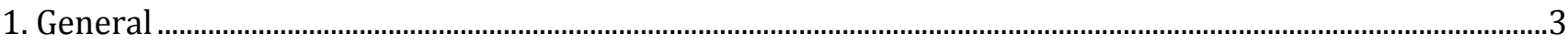

2. Strain

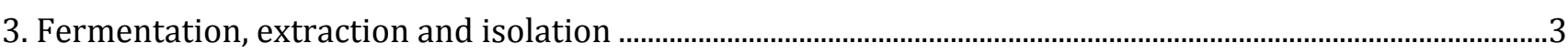

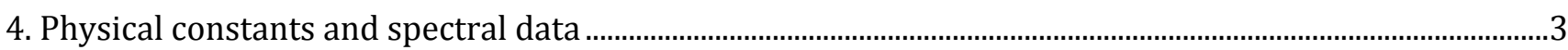

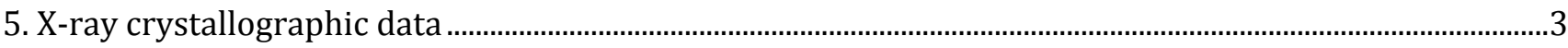

6. Computational details...................................................................................................................................

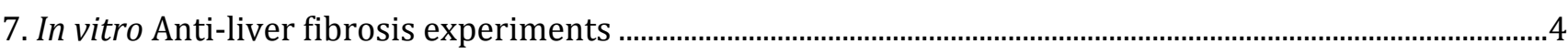

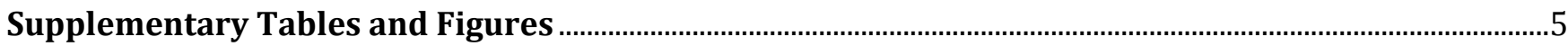

Table S1. Experimental and Computed ${ }^{13} \mathrm{C}$ NMR Data for 1

Table S2. The primers used in vitro anti-liver fibrosis assays...............................................................................

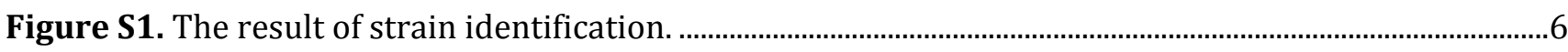

Figure S2. ORTEP drawing of the crystal structure of 2. ..............................................................................

Figure S3. Linear correlation between the experimental and calculated ${ }^{13} \mathrm{C}$ NMR chemical shifts for 1 .....8

Table S3. Experimental and calculated ${ }^{13} \mathrm{C}$ NMR chemical shifts for 1 .............................................................8

Scheme S1. Hypothetical biosynthetic pathways for 1 and 2 . ..........................................................................

Figure S4. Compounds 1-2 inhibited the expression of COL1A1 in LX-2 cells.................................................10

Figure S5. Compound 1-2 repressed fibrogenic genes expression in LX-2 cells.............................................10

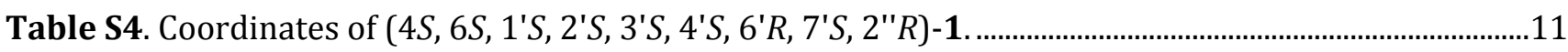

Figure S6. ${ }^{1} \mathrm{H}$ NMR spectrum (DMSO- $d_{6}, 500 \mathrm{MHz}$ ) of compound 1...............................................................12

Figure S7. ${ }^{13} \mathrm{C}$ NMR spectrum (DMSO- $d_{6}, 125 \mathrm{MHz}$ ) of compound 1 . …..........................................................13

Figure S8. ${ }^{1} \mathrm{H}-{ }^{1} \mathrm{H}$ COSY spectrum (DMSO- $d_{6}, 600 \mathrm{MHz}$ ) of compound 1.......................................................14

Figure S9. HSQC spectrum (DMSO- $d_{6}, 600 \mathrm{MHz}$ ) of compound 1..............................................................15

Figure S10. HMBC spectrum (DMSO- $d_{6}, 600 \mathrm{MHz}$ ) of compound 1.................................................................16

Figure S11. REOSY spectrum (DMSO- $d_{6}, 600 \mathrm{MHz}$ ) of compound 1.............................................................17

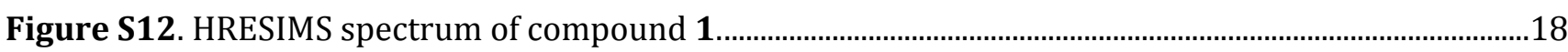

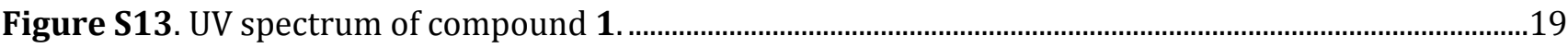

Figure S14. IR spectrum of compound 1

Figure S15. ${ }^{1} \mathrm{H}$ NMR spectrum (DMSO- $d_{6}, 500 \mathrm{MHz}$ ) of compound 2..........................................................21

Figure S16. ${ }^{13} \mathrm{C}$ NMR spectrum (DMSO- $d_{6}, 125 \mathrm{MHz}$ ) of compound 2 . .........................................................22

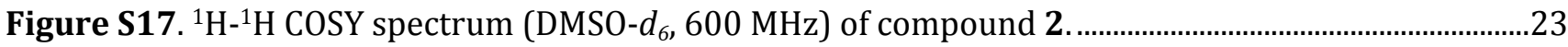

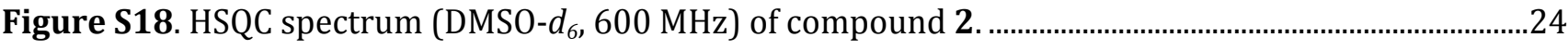

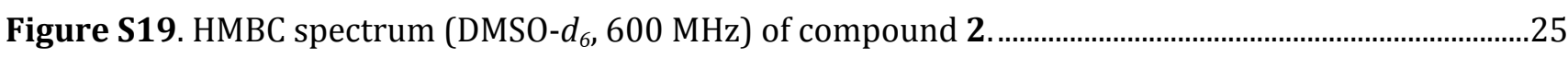

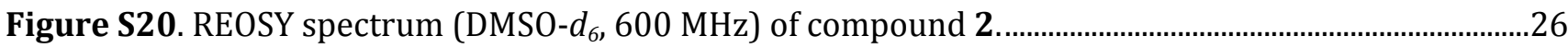

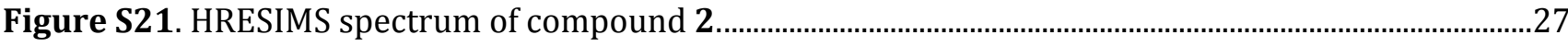

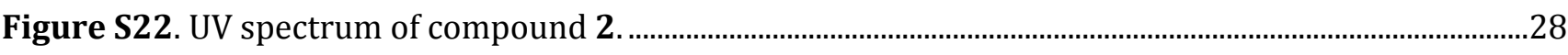

Figure S23. IR spectrum of compound 2 


\section{Experimental Procedures}

\section{General}

Optical rotations were measured on a JASCO P-1020 polarimeter. UV spectra were obtained on a Shimadzu UV-2450 spectrophotometer. IR spectra were recorded in $\mathrm{KBr}$-disc on a Bruker Tensor 27 spectrometer. ECD spectra were determined on a Jasco 810 spectrometer. NMR data were performed on a Bruker AV-600 and AV-500 NMR instrument with DMSO or $\mathrm{CD}_{3} \mathrm{OD}$ as solvent. HRESIMS was recorded on an Agilent 6520B Q-TOF mass instrument. Preparative HPLC was performed on a Shimadzu LC-6AD series instrument with a Shim-park RP-C18 column $(20 \times 200 \mathrm{~mm})$ and a Phenomenex Lux $5 \mathrm{u}$ Cellulose- 2 column $(250 \mathrm{~mm} \times 21.2 \mathrm{~mm}, 5 \mu \mathrm{m})$, detected by a binary channel UV detector at 210 and $254 \mathrm{~nm}$. PCR was accomplished using Applied Biosystems ${ }^{\mathrm{TM}}$ Veriti $^{\mathrm{TM}}$ 96-well Thermal Cycler (Life Technologies). Quantitative Reverse-Transcription PCR (RT-qPCR) was carried out on the QuantStudio ${ }^{\circledR} 3$ real-time PCR System (Applied Biosystems). All solvents used were analytical grade (Jiangsu Hanbon Science and Technology. Co., Ltd.). Silica gel (Qingdao Haiyang Chemical Co. Ltd., Qingdao, China), Sephadex LH-20 (Pharmacia, New Jersey, USA), and MCI gel (Mitsubishi Chemical Corp., Tokyo, Japan) were used for column chromatography.

\section{Strain}

The fungal strain Epicoccum nigrum (W-2) was isolated from the stem tuber of Pinellia ternate (thunb.) Berit. which were collected from the Gansu Province, China, in September 2016. It was authenticated on the basis of morphological studies, reinforced by 5.8S rRNA and internal transcribed spacer (ITS) sequences with $100 \%$ identity to the known E. nigrum. (Figure S1).

\section{Fermentation, extraction and isolation}

Proper mycelia of strains were inoculated on potato dextrose agar (PDA) plates for 4 days at $28{ }^{\circ} \mathrm{C}$ under static conditions. Three pieces $\left(0.3 \times 0.3 \times 0.3 \mathrm{~cm}^{3}\right)$ of agar plugs were transferred aseptically into a $500 \mathrm{~mL}$ Erlenmeyer flask containing 200 $\mathrm{mL}$ of potato dextrose liquid medium, incubated on a rotary shaker at $28{ }^{\circ} \mathrm{C}$ and $180 \mathrm{rpm}$ for 4 days to prepare seed culture. Solid fermentation was carried out in 5 Erlenmeyer flasks $(2.5 \mathrm{~L})$ each containing $320 \mathrm{~g}$ of sterilized rice and $70 \mathrm{~mL}$ of seed culture at $28^{\circ} \mathrm{C}$ for 45 days.

The rice cultures were extracted with EtOAc three times at room temperature. After removal of the solvent under reduced pressure, the crude extract ( $25 \mathrm{~g}$ ) was submitted to silica gel using a step gradient of $\mathrm{CH}_{2} \mathrm{Cl}_{2} / \mathrm{MeOH}$ to obtain fractions A-F The epicolactones were gathered by solvent $\mathrm{CH}_{2} \mathrm{Cl}_{2}-\mathrm{MeOH}(\mathrm{v} / \mathrm{v}, 20: 1)$ in silica gel chromatography (fraction C), which was further separated by MCI chromatography with methanol and water $(20 \%, 25 \%, 30 \%, 35 \%$ and $45 \%$ methanol) as solvent to obtain fractions C1-C8. Fractions C3 and C4 were respectively purified by Sephadex $\mathrm{LH}-20$ with $\mathrm{CH}_{2} \mathrm{Cl}_{2}-\mathrm{MeOH}(\mathrm{v} / \mathrm{v}, 1: 1)$ to gather dimers to fractions C3.1, C3.2, C4.1, C4.2. Compound 1 was obtained from fraction C4.1 ( $\mathrm{t}_{\mathrm{R}} 56.7 \mathrm{~min}, 3.0 \mathrm{mg}$ ) by preparative $\mathrm{HPLC}\left(\mathrm{ACN}-\mathrm{H}_{2} \mathrm{O}, 18: 82, \mathrm{v} / \mathrm{v}, 10.0 \mathrm{~mL} / \mathrm{min}\right)$. Compound 2 was isolated from fraction $\mathrm{C} 3.1\left(\mathrm{t}_{\mathrm{R}} 55.7 \mathrm{~min}, 5.2 \mathrm{mg}\right)$ by preparative HPLC $\left(\mathrm{ACN}-\mathrm{H}_{2} \mathrm{O}, 18: 82, \mathrm{v} / \mathrm{v}, 10.0 \mathrm{~mL} / \mathrm{min}\right)$.

\section{Physical constants and spectral data}

Beetleane A (1) was obtained as a white powder. HRMS (ESI) $m / z$ : [M+NH$]^{+}$calcd for $\mathrm{C}_{21} \mathrm{H}_{26} \mathrm{NO}_{9}$ 436.1602; found 436.1601; $[\alpha]^{25}+7.6$ (c 0.1, MeOH); UV (MeOH) $\lambda_{\max }(\log \varepsilon)=202$ (3.82), $214(3.77), 248$ (4.09) nm; IR $v_{\max }=3436,1789,1734,1662$, $1385,1203,1170,1103,997,961,919,894 \mathrm{~cm}^{-1}$. For ${ }^{1} \mathrm{H}$ NMR and ${ }^{13} \mathrm{C}$ NMR data see Table 1.

Epicoane A (2) was obtained as a white powder. HRMS (ESI) $m / z$ [M+Na] ${ }^{+}$calcd for $\mathrm{C}_{21} \mathrm{H}_{22} \mathrm{NaO}_{9}$ 441.1156; found 441.1155; $[\alpha]^{25}+10.4(\mathrm{c} \mathrm{0.1}, \mathrm{MeOH})$; UV (MeOH) $\lambda_{\max }(\log \varepsilon)=203$ (3.97), 217 (3.89), 247 (4.09) nm; IR $v_{\max }=3350,1660,1451,1339$, $1248,1213,1110,1089,1048,928,906,874 \mathrm{~cm}^{-1}$. For ${ }^{1} \mathrm{H}$ NMR and ${ }^{13} \mathrm{C}$ NMR data see Table 1.

\section{X-ray crystallographic data}

X-ray crystallographic data for compound 2. Upon crystallization from $\mathrm{MeOH}$ using the vapor diffusion method, colorless crystalline crystals of $\mathbf{2}$ were obtained. A suitable crystal was selected and tested on a Bruker APEX-II CCD diffractometer. Crystal Data: $\mathrm{C}_{21} \mathrm{H}_{22} \mathrm{O}_{9}(M=418.38 \mathrm{~g} / \mathrm{mol})$ : monoclinic, space group P2 $2_{1}$ (no. 4), $a=15.9549(5) \AA, b=8.1812(4) \AA, c=$ $15.9741(5) \AA, \alpha=90^{\circ}, \beta=117.2340(10)^{\circ}, \gamma=90^{\circ} V=1853.96(12) \AA^{3}, Z=4, T=170.0 \mathrm{~K}, \mu(\mathrm{CuK} \alpha)=1.001 \mathrm{~mm}^{-1}$, Dcalc $=1.499$ $\mathrm{g} / \mathrm{cm}^{3}, 12292$ reflections measured $\left(6.222^{\circ} \leq 2 \Theta \leq 149.136^{\circ}\right), 6442$ unique $\left(R_{\text {int }}=0.0464, \mathrm{R}_{\text {sigma }}=0.0609\right)$ which were used in all calculations. The final $\mathrm{R}_{1}$ was 0.0468 ( $\mathrm{I}>2 \sigma(\mathrm{I})$ ) and wR2 was 0.1353 (all data). The goodness of fit on $F^{2}$ was 1.073 . Flack parameter $=0.04(10)$. Crystallographic data for 2 have been deposited at the Cambridge Crystallographic Data Center (deposition number CCDC 2057641). Copies of the data can be obtained free of charge via www.ccdc.cam.ac.uk/conts/retrieving.html or from the Cambridge Crystallographic Data Centre, 12, Union Road, Cambridge CB2 1EZ, U.K. [fax (+44) 1223-336-033; or e-mail: deposit@ccdc.cam.ac.uk]. 


\section{Computational details}

Monte Carlo conformational searches were carried out by means of the Spartan' 10 software (Wavefunction, Inc., Irvine, CA) using Merck molecular force field (MMFF). The conformers with Boltzmann-population of over 5\% were chosen for geometrical optimization at B3LYP/6-31+G $(d, p)$ level in $\mathrm{MeOH}$ using the CPCM polarizable conductor calculation model by Gaussian 09 package.

NMR calculations for 1 . NMR chemical shifts were computed at the B3LYP/6-311+G(2d,p) level using the GIAO method in DMSO simulated by the IEFPCM model. Finally, the TMS-corrected NMR chemical shift values were averaged according to Boltzmann distribution and fitted to the experimental values by linear regression. For each stereoisomer, the parameters $a$ and $b$ of the linear regression $\delta_{\text {cal }}=a \delta_{\text {exp }}+b$; the correlation coefficient, $R^{2}=0.9982$; the mean absolute error (MAE) defined as $\Sigma \mathrm{n}\left|\delta_{\text {cal }}-\delta_{\text {exp }}\right| / n$; the corrected mean absolute error, CMAE, defined as $\Sigma \mathrm{n}\left|\delta_{\text {corr }}-\delta_{\text {exp }}\right| / n ; \delta_{\text {corr }}=\left(\delta_{\text {cal }}-b\right) / a$ used to correct systematic errors, are presented in Table S1 and Figure S3 $(a=0.9614, b=3.29095)$.

ECD calculations for 1 . The calculations were executed in methanol with IEFPCM model using time-dependent density functional theory (TD-DFT) at the B3LYP/6-31+G(2d,p) level. Rotatory strengths for a total of 40 excited states were calculated. ECD spectra were generated using SpecDis 1.7 with a half-bandwidth of $0.25 \mathrm{eV}$, and the final ECD spectra were constructed based on the Boltzmann-weighting according to their population contribution. And the UV-shift values were -5 nm for $\left(4 S, 6 S, 1^{\prime} S, 2 ' S, 3 ' S, 4 ' S, 6^{\prime} R, 7 ' S, 2 " R\right)-1$.

\section{In vitro Anti-liver fibrosis experiments}

Cell culture. LX-2 cells were received as a generous gift from Scott Friedman (Mount Sinai School of Medicine, New York). Cell lines were routinely tested for mycoplasma. LX-2 cells supplemented with $10 \%$ FBS and 1\% penicillin/streptomycin (Invitrogen, Carlsbad, CA, USA). These cells were grown in a humidified incubator of $5 \% \mathrm{CO}_{2}$ in air at $37^{\circ} \mathrm{C}$.

Luciferase Reporter Assay. The pGL4.17-COL1A1 luciferase reporter plasmid is gift from Hongwei He (Peking Union Medical College, Beijing). Upon reaching 60-80\% confluences, the cells were starved in serum-free DMEM for $24 \mathrm{~h}$ prior to treatment with $2 \mathrm{ng} \cdot \mathrm{m}^{-1}$ TGF $\beta 1$. Plasmids of pGL4-Col1A1 were transfected in LX2 cells. After transfection for $24 \mathrm{~h}$, LX2 cells were respectively treated with $20 \mu \mathrm{M}$ compounds 1-2 for $24 \mathrm{~h}$ and then lysed for luciferase activity with a Duo-LiteTM Luciferase Assay System (Vazyme Biotech Co., Ltd).

RT-qPCR analysis. Total RNA was extracted from the LX-2 cells using Tripure reagent (Roche Diagnostics, Indianapolis, IN) as described by the manufacturer. DNA synthesis was carried out with HiScript ${ }^{\circ}$ II Q Select RT SuperMix for qPCR (Vazyme Biotech Co., Ltd). Quantitative PCR was performed in biological triplicates using SYBR Green reagent (Vazyme Biotech Co., Ltd). The level of GAPDH (human) RNA expression was used to normalize the data. PCR primer sequences were listed in Table S2. A melting curve of each amplicon was determined to verify its specificity.

Quantitative and statistical analysis All data were expressed as mean \pm SEM. Statistical differences between two groups were analyzed by the unpaired Student's t test with a two-tailed distribution. Differences between multiple groups of data were analyzed by one-way ANOVA with Bonferroni correction (Graph Pad Prism 5.0). A $p$ values $<0.05$ was considered statistically significant. 


\section{Supplementary Tables and Figures}

Table S1. Experimental and Computed ${ }^{13} \mathrm{C}$ NMR Data for $\mathbf{1}$

\begin{tabular}{|c|c|c|c|c|c|}
\hline \multirow[b]{2}{*}{ position } & \multicolumn{5}{|c|}{$\mathbf{1}(\delta, \mathrm{ppm})$} \\
\hline & $\delta_{c}$, exptl $^{\mathrm{a}}$ & $\overline{\delta_{\mathrm{C}}, \text { calcd }^{\mathrm{b}}}$ & $\overline{\delta_{C}{ }^{c}}$ & $\delta_{C}$, corre $^{\mathrm{d}}$ & $\overline{\delta_{C}{ }^{\mathrm{e}}}$ \\
\hline 1 & 75.0 & 75.0 & 0.0 & 75.4 & 0.4 \\
\hline 2 & 135.8 & 136.9 & 1.1 & 134.9 & 0.9 \\
\hline 3 & 167.1 & 166.1 & 1.0 & 163.0 & 4.1 \\
\hline 4 & 83.0 & 84.5 & 1.5 & 84.5 & 1.5 \\
\hline 5 & 200.1 & 204.1 & 4.0 & 199.5 & 0.6 \\
\hline 6 & 54.2 & 57.2 & 3.0 & 58.3 & 4.1 \\
\hline 7 & 129.4 & 131.1 & 1.7 & 129.4 & 0.0 \\
\hline 8 & 76.8 & 72.8 & 4.0 & 73.3 & 3.5 \\
\hline 9 & 15.8 & 10.9 & 4.9 & 13.8 & 2.0 \\
\hline $1^{\prime}$ & 73.7 & 71.9 & 1.8 & 72.4 & 1.3 \\
\hline $2^{\prime}$ & 56.0 & 59.8 & 3.8 & 60.8 & 4.8 \\
\hline $3^{\prime}$ & 109.4 & 111.1 & 1.7 & 110.1 & 0.7 \\
\hline $4^{\prime}$ & 83.4 & 85.5 & 2.1 & 85.5 & 2.1 \\
\hline $5^{\prime}$ & 202.0 & 209.0 & 7.0 & 204.2 & 2.2 \\
\hline $6^{\prime}$ & 43.8 & 44.2 & 0.4 & 45.8 & 2.0 \\
\hline $7^{\prime}$ & 58.0 & 58.2 & 0.2 & 59.2 & 1.2 \\
\hline $8^{\prime}$ & 70.6 & 67.7 & 2.9 & 68.4 & 2.2 \\
\hline $9^{\prime}$ & 15.5 & 12.2 & 3.3 & 15.0 & 0.5 \\
\hline $1^{\prime \prime}$ & 36.7 & 33.5 & 3.2 & 35.5 & 1.2 \\
\hline $2^{\prime \prime}$ & 65.9 & 64.7 & 1.2 & 65.5 & 0.4 \\
\hline $3 "$ & 20.2 & 15.2 & 5.0 & 17.9 & 2.3 \\
\hline
\end{tabular}

${ }^{a}$ Recorded in DMSO- $d_{6}$ at $125 \mathrm{MHz} .{ }^{b}$ Calculated in DMSO- $d_{6} \cdot{ }^{\mathrm{d}}$ Correction was used to correct systematic errors. ${ }^{c} \Delta \delta_{\mathrm{C}}=\left|\delta_{\text {calcd }}-\delta_{\text {exptl }}\right|, \mathrm{MAE}=2.6 \mathrm{ppm}$, and ${ }^{e} \Delta \delta_{\mathrm{C}}=\left|\delta_{\text {corre }}-\delta_{\text {exptl }}\right|$, $\mathrm{CMAE}=1.8 \mathrm{ppm}$.

Table S2. The primers used in vitro anti-liver fibrosis assays.

\begin{tabular}{llll}
\hline Species & Gene & Forward primer & Reverse primer \\
\hline Human & GAPDH & GACCTGCCGTCTAGAAAAAC & TTGAAGTCAGAGGAGACCAC \\
\cline { 2 - 4 } & ACTA2 & CCTTGTTTGGGAAGCAAGTGG & TGGAGCTGCTTCACAGGATT \\
\cline { 2 - 4 } & COL1A1 & GTGCGATGACGTGATCTGTGA & CGGTGGTTTCTTGGTCGGT \\
\hline
\end{tabular}




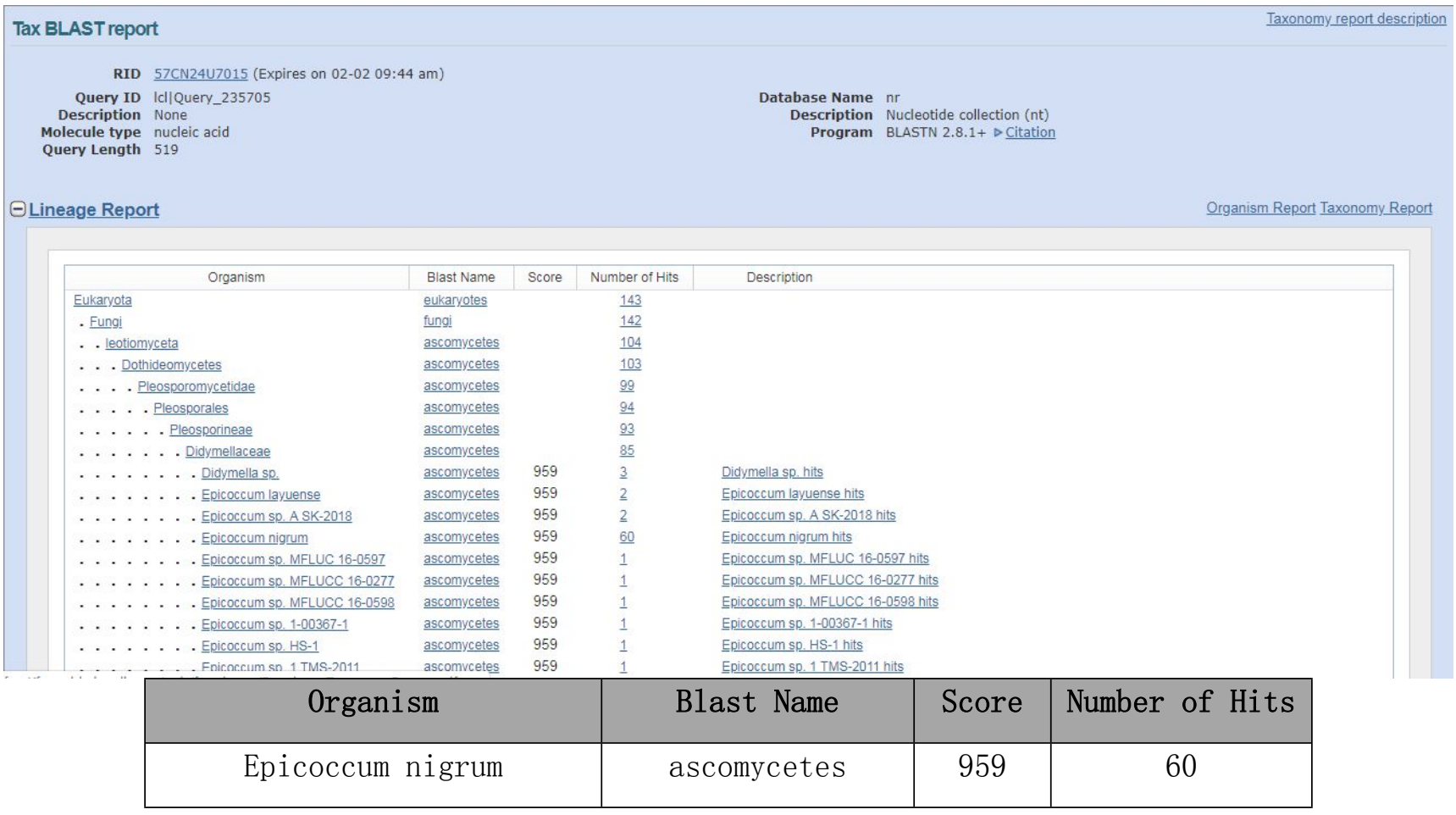

Figure S1. The result of strain identification. 


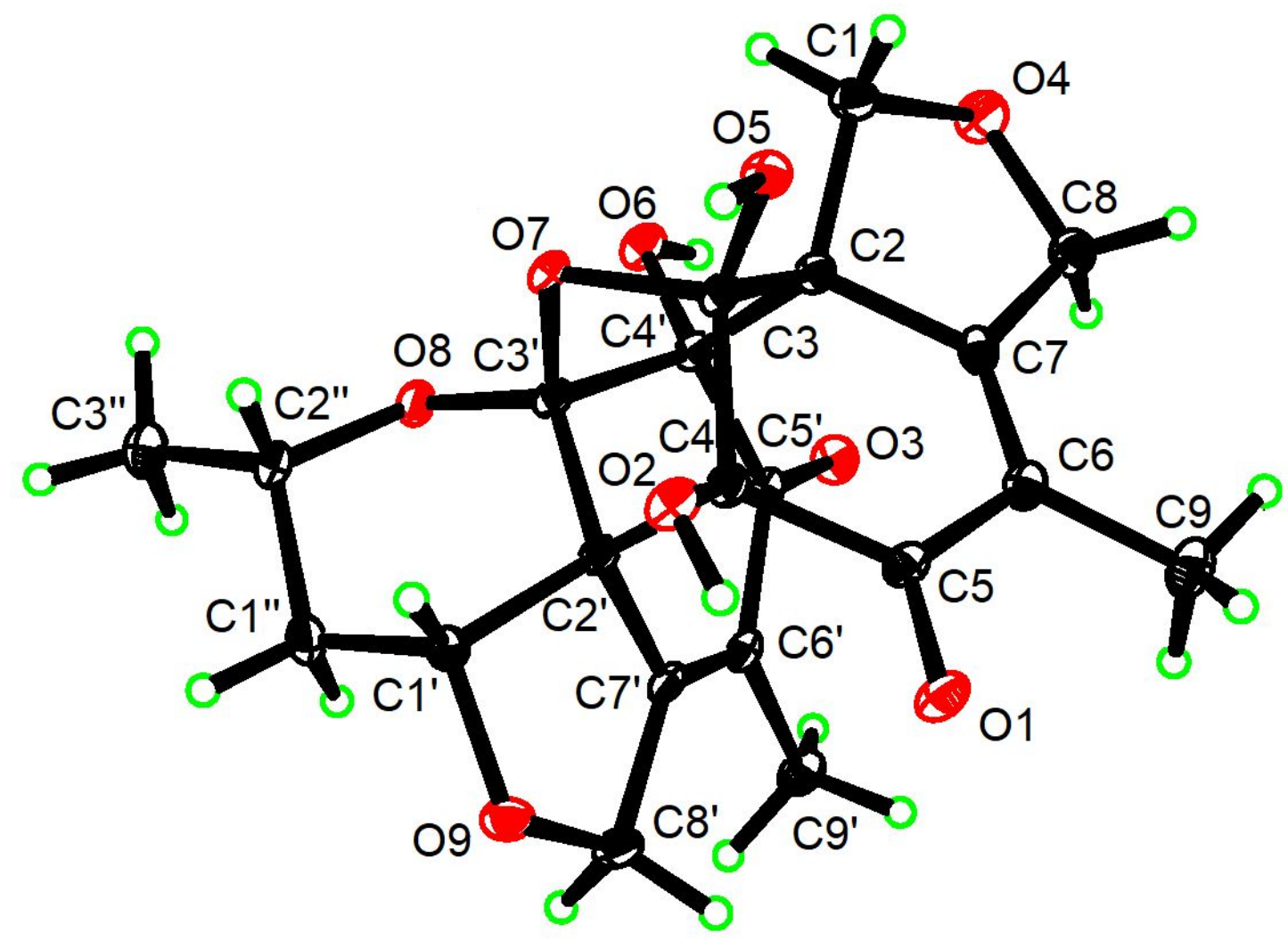

Figure S2. ORTEP drawing of the crystal structure of 2. Displacement ellipsoids are drawn at the 50\% probability level.

Crystal data for compound 5: $\mathrm{C}_{21} \mathrm{H}_{22} \mathrm{O}_{9}(M=418.38 \mathrm{~g} / \mathrm{mol})$ : monoclinic, space group P2 1 (no. 4), $a=15.9549(5) \AA, b=$ 8.1812(4) $\AA, c=15.9741(5) \AA, \alpha=90^{\circ}, \beta=117.2340(10)^{\circ}, \gamma=90^{\circ} V=1853.96(12) \AA^{3}, Z=4, T=170.0 \mathrm{~K}, \mu(\mathrm{CuK} \alpha)=1.001$ $\mathrm{mm}^{-1}$, Dcalc $=1.499 \mathrm{~g} / \mathrm{cm}^{3}, 12292$ reflections measured $\left(6.222^{\circ} \leq 2 \Theta \leq 149.136^{\circ}\right), 6442$ unique $\left(R_{\text {int }}=0.0464, \mathrm{R}_{\text {sigma }}=0.0609\right)$ which were used in all calculations. The final $R_{1}$ was 0.0468 (I > $2 \sigma(I)$ ) and wR2 was 0.1353 (all data). The goodness of fit on $F^{2}$ was 1.073. Flack parameter $=0.04(10)$. 


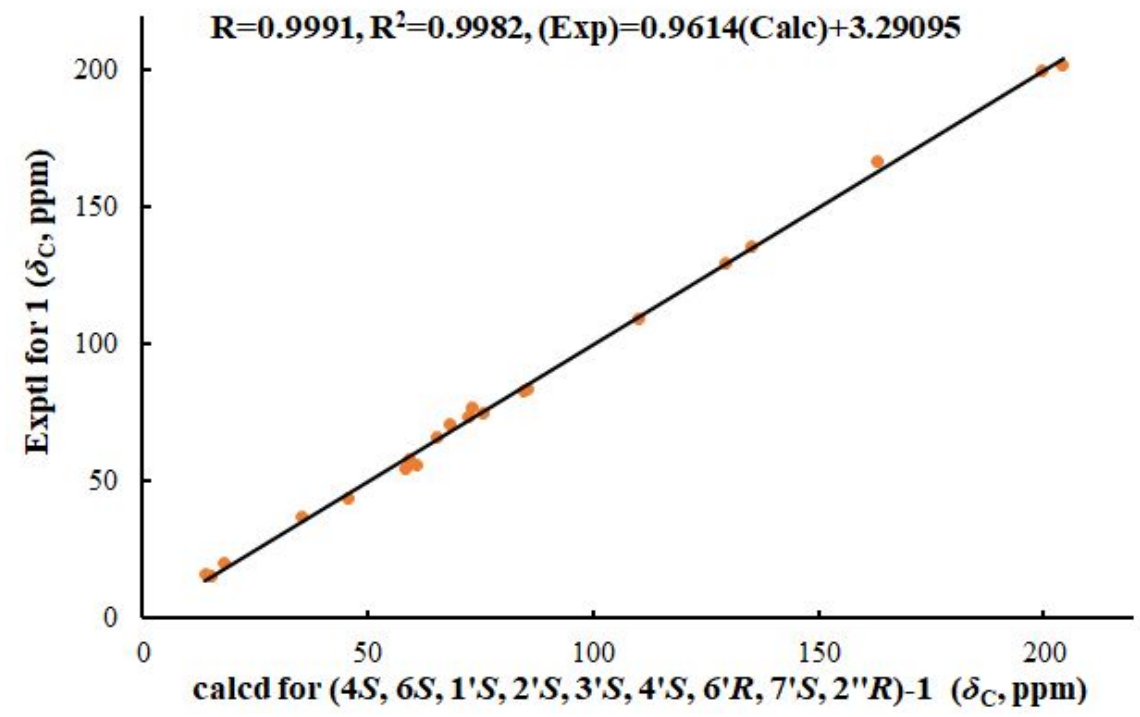

Figure S3. Linear correlation between the experimental and calculated ${ }^{13} \mathrm{C}$ NMR chemical shifts for 1.

Table S3. Experimental and calculated ${ }^{13} \mathrm{C}$ NMR chemical shifts for $\mathbf{1}$.

\begin{tabular}{ccc}
\hline & \multicolumn{2}{c}{$\mathbf{1}(\delta, \mathrm{ppm})$} \\
\cline { 2 - 3 } carbon & Experimental & Calculated \\
\hline 2 & 75.0 & 75.4 \\
3 & 135.8 & 134.9 \\
4 & 167.1 & 163.0 \\
5 & 83.0 & 84.5 \\
6 & 200.1 & 199.5 \\
7 & 54.2 & 58.3 \\
8 & 129.4 & 129.4 \\
9 & 76.8 & 73.3 \\
$1^{\prime}$ & 15.8 & 13.8 \\
$2^{\prime}$ & 73.7 & 72.4 \\
$3^{\prime}$ & 56.0 & 60.8 \\
$4^{\prime}$ & 109.4 & 110.1 \\
$5^{\prime}$ & 83.4 & 85.5 \\
$6^{\prime}$ & 202.0 & 204.2 \\
$7^{\prime}$ & 43.8 & 45.8 \\
$8^{\prime}$ & 58.0 & 59.2 \\
$9^{\prime}$ & 70.6 & 68.4 \\
$1^{\prime \prime}$ & 15.5 & 15.0 \\
$2^{\prime \prime}$ & 36.7 & 35.5 \\
$3^{\prime \prime}$ & 65.9 & 65.5 \\
\hline
\end{tabular}




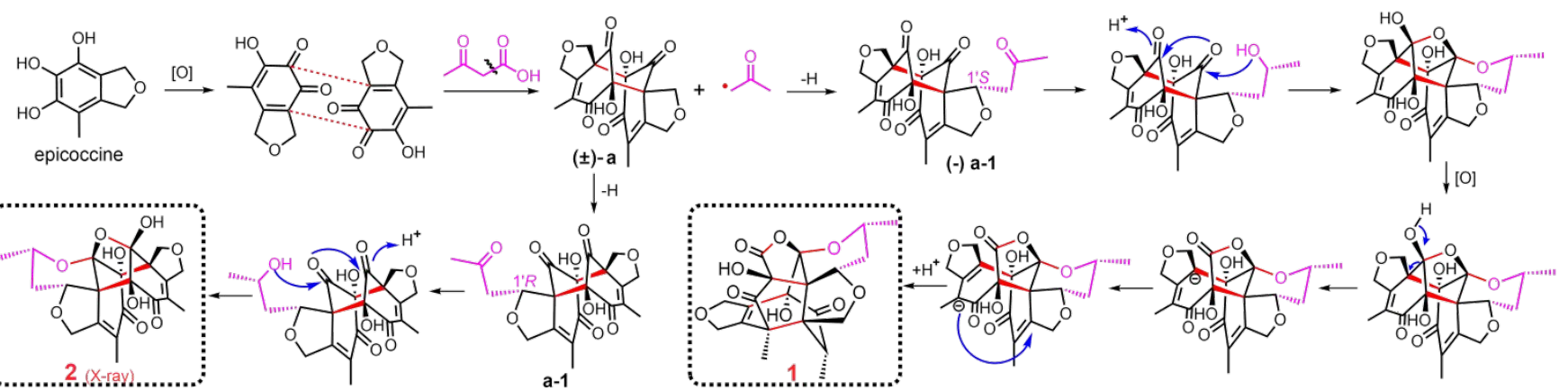

Scheme S1. Hypothetical biosynthetic pathways for 1 and 2. The negative sign of (-) a-1 only indicates it is the enantiomer of a-1, not a real sign of its optical rotation. 


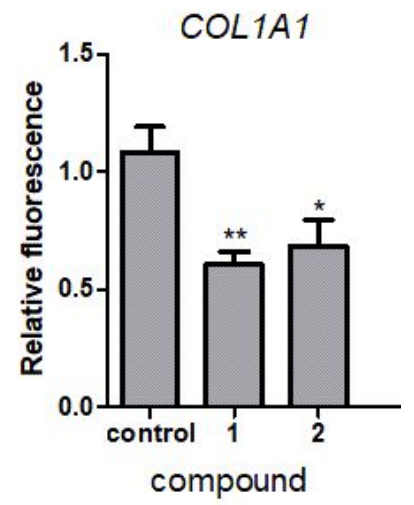

Figure S4. Compounds 1-2 inhibited the expression of COL1A1 in LX-2 cells.
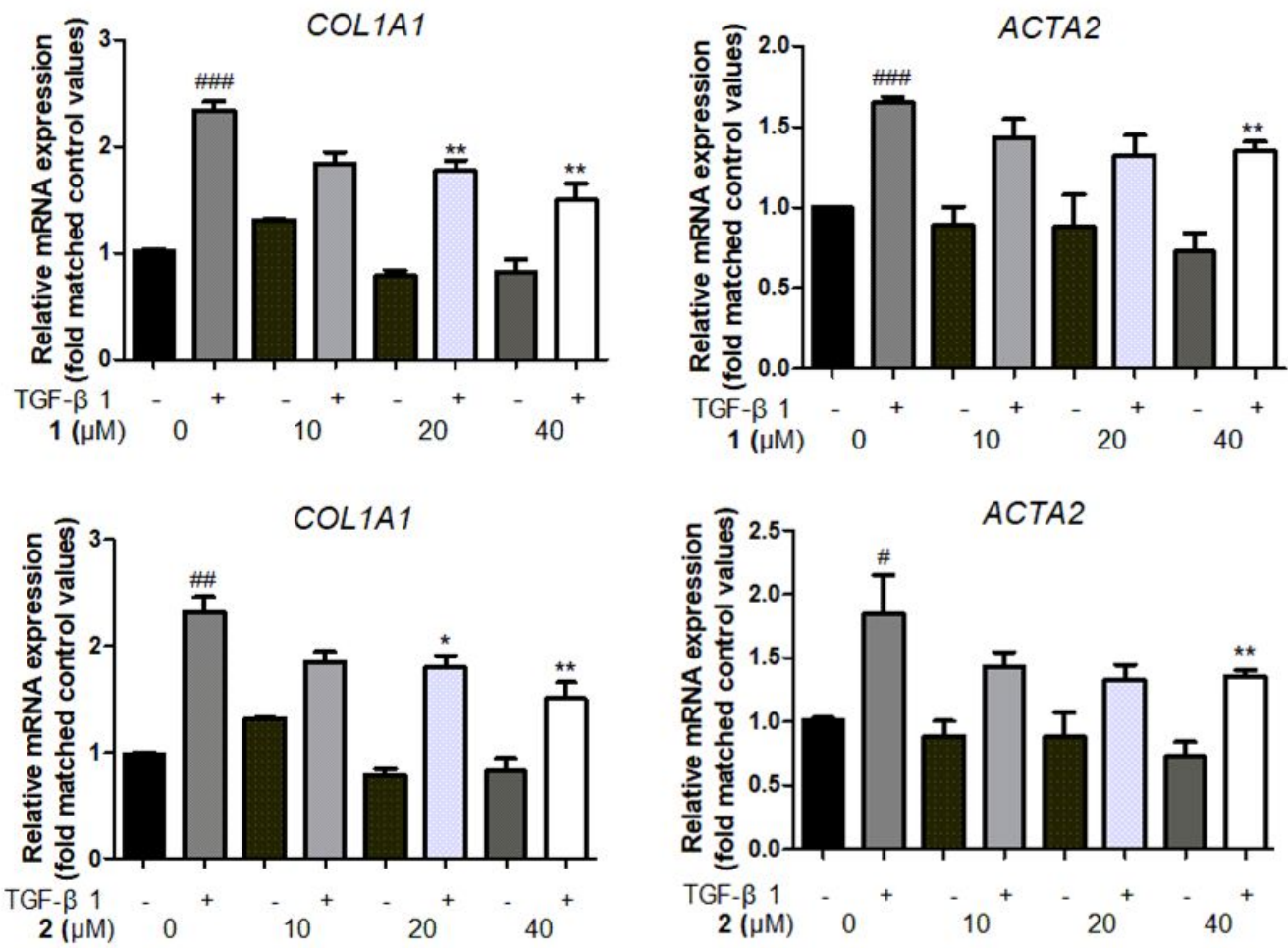

Figure S5. Compound 1-2 repressed fibrogenic genes expression in LX-2 cells.

LX-2 cells were incubated in serum-free medium for $12 \mathrm{~h}$, followed by treatment with compound $\mathbf{1}$ and $2(10 \mu \mathrm{M}, 20 \mu \mathrm{M}, 40$ $\mu \mathrm{M})$ respectively for $24 \mathrm{~h}$ in the presence or absence of TGF- $\beta 1(2 \mathrm{ng} / \mathrm{mL})$ for $6 \mathrm{~h}$. COL1A1 and ACTA2 were measured by RTqPCR. (Data are presented as means \pm SEM. ${ }^{\#} p<0.05$; ${ }^{\# \# ~} p<0.001$; significantly different from control group; * $p<0.05$; ${ }^{* *}$ $p<0.01$; significantly different from TGF- $\beta 1$ group.) 
Table S4. Coordinates of $\left(4 S, 6 S, 1^{\prime} S, 2 ' S, 3 ' S, 4 ' S, 6^{\prime} R, 7^{\prime} S, 22^{\prime \prime} R\right)-1$.

\begin{tabular}{|c|c|c|c|c|c|}
\hline \multirow{2}{*}{ Center Number } & \multirow{2}{*}{ Atomic Number } & \multirow{2}{*}{ Atomic Type } & \multicolumn{3}{|c|}{ Corrdinates (Angstroms) } \\
\hline & & & $\mathrm{X}$ & $\mathrm{Y}$ & $\mathrm{Z}$ \\
\hline 1 & 6 & 0 & 3.356114 & 0.207389 & -0.673068 \\
\hline 2 & 6 & 0 & 3.325727 & -0.475573 & 0.689262 \\
\hline 3 & 6 & 0 & 2.066091 & -1.329376 & 0.815238 \\
\hline 4 & 6 & 0 & 0.967611 & 0.51891 & -0.767943 \\
\hline 5 & 6 & 0 & -0.022168 & 1.685022 & -0.432068 \\
\hline 6 & 8 & 0 & 0.256887 & 2.809396 & -1.21622 \\
\hline 7 & 6 & 0 & -1.477216 & 1.306059 & -0.598809 \\
\hline 8 & 6 & 0 & 0.181048 & 2.012947 & 1.054465 \\
\hline 9 & 6 & 0 & 0.036333 & 0.86989 & 2.0454 \\
\hline 10 & 6 & 0 & -0.206676 & -0.511302 & 1.374273 \\
\hline 11 & 6 & 0 & -1.64226 & -0.812937 & 0.842662 \\
\hline 12 & 6 & 0 & -2.17267 & 0.316126 & -0.018025 \\
\hline 13 & 6 & 0 & 0.768858 & -0.744527 & 0.152228 \\
\hline 14 & 8 & 0 & 1.747932 & -1.514441 & 2.202062 \\
\hline 15 & 6 & 0 & 0.338744 & -1.614521 & 2.31389 \\
\hline 16 & 8 & 0 & -2.126947 & -2.781763 & -0.559814 \\
\hline 17 & 8 & 0 & 0.694024 & 0.084486 & -2.124564 \\
\hline 18 & 6 & 0 & 0.121811 & -1.140548 & -2.177357 \\
\hline 19 & 6 & 0 & -3.606885 & 0.376957 & -0.499394 \\
\hline 20 & 6 & 0 & -2.389925 & 2.122707 & -1.477341 \\
\hline 21 & 8 & 0 & -3.680156 & 1.530471 & -1.329107 \\
\hline 22 & 6 & 0 & -2.673489 & -1.310178 & 1.869253 \\
\hline 23 & 8 & 0 & 0.448962 & 3.152609 & 1.383782 \\
\hline 24 & 8 & 0 & 2.219176 & 1.097276 & -0.724282 \\
\hline 25 & 6 & 0 & 4.585573 & 1.067722 & -0.912677 \\
\hline 26 & 8 & 0 & 0.636572 & -3.048591 & -0.818441 \\
\hline 27 & 8 & 0 & -0.220193 & -1.681004 & -3.195035 \\
\hline 28 & 6 & 0 & 0.057747 & -1.758733 & -0.774051 \\
\hline 29 & 6 & 0 & -1.375525 & -1.89953 & -0.216944 \\
\hline 30 & 6 & 0 & -0.946815 & 1.275495 & 3.162228 \\
\hline 31 & 1 & 0 & 3.259246 & -0.531373 & -1.481549 \\
\hline 32 & 1 & 0 & 3.33549 & 0.297974 & 1.465749 \\
\hline 33 & 1 & 0 & 4.211279 & -1.103689 & 0.836562 \\
\hline 34 & 1 & 0 & 2.252576 & -2.307826 & 0.363983 \\
\hline 35 & 1 & 0 & 0.634179 & 3.469449 & -0.600515 \\
\hline 36 & 1 & 0 & 1.028956 & 0.792624 & 2.511814 \\
\hline 37 & 1 & 0 & 0.078896 & -1.471089 & 3.365685 \\
\hline 38 & 1 & 0 & -0.01147 & -2.610932 & 2.000629 \\
\hline 39 & 1 & 0 & -4.32301 & 0.476247 & 0.330399 \\
\hline 40 & 1 & 0 & -3.887879 & -0.526458 & -1.065053 \\
\hline 41 & 1 & 0 & -2.425166 & 3.178796 & -1.178247 \\
\hline 42 & 1 & 0 & -2.065353 & 2.091061 & -2.52768 \\
\hline 43 & 1 & 0 & -2.252505 & -2.097287 & 2.501416 \\
\hline 44 & 1 & 0 & -3.029568 & -0.504376 & 2.514324 \\
\hline 45 & 1 & 0 & -3.530479 & -1.744966 & 1.347141 \\
\hline 46 & 1 & 0 & 4.679019 & 1.829245 & -0.131075 \\
\hline 47 & 1 & 0 & 4.514181 & 1.571725 & -1.880686 \\
\hline 48 & 1 & 0 & 5.488094 & 0.447615 & -0.905416 \\
\hline 49 & 1 & 0 & 0.036631 & -3.580346 & -1.374453 \\
\hline 50 & 1 & 0 & -0.592957 & 2.198245 & 3.628701 \\
\hline 51 & 1 & 0 & -1.949975 & 1.462285 & 2.769105 \\
\hline 52 & 1 & 0 & -1.012408 & 0.503563 & 3.9348 \\
\hline
\end{tabular}


NMR, HRESIMS, UV, and IR spectra of compound 1 范

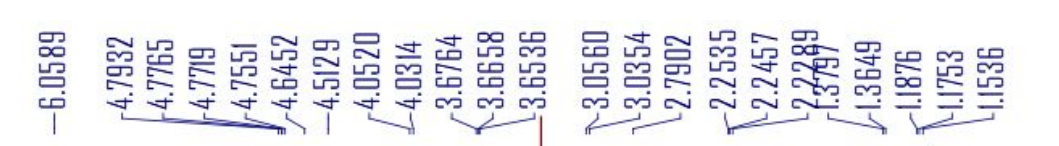
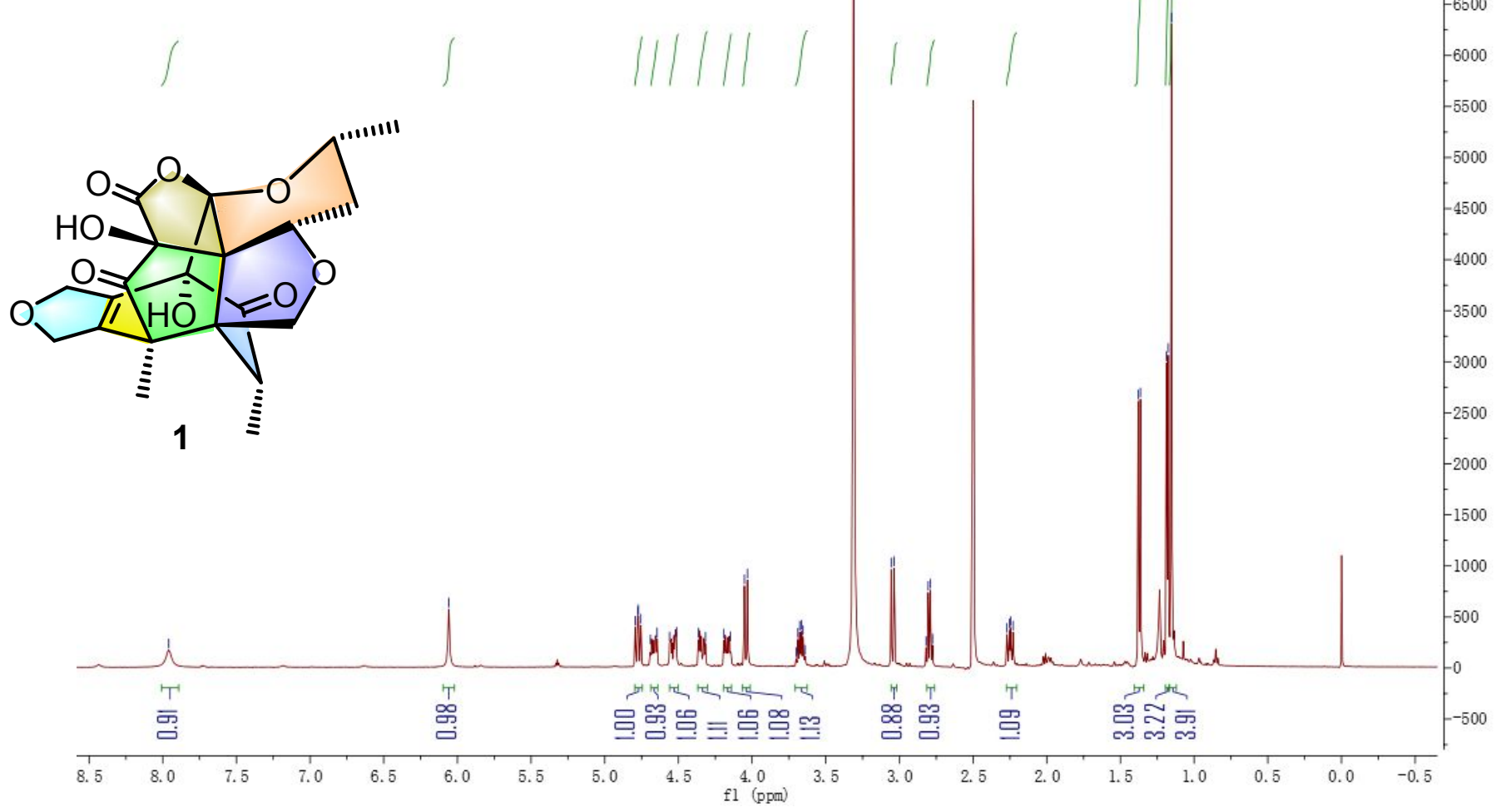

Figure S6. ${ }^{1} \mathrm{H}$ NMR spectrum (DMSO- $d_{6}, 500 \mathrm{MHz}$ ) of compound 1. 


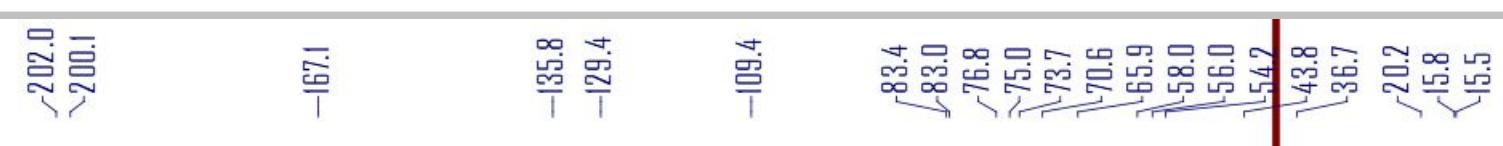
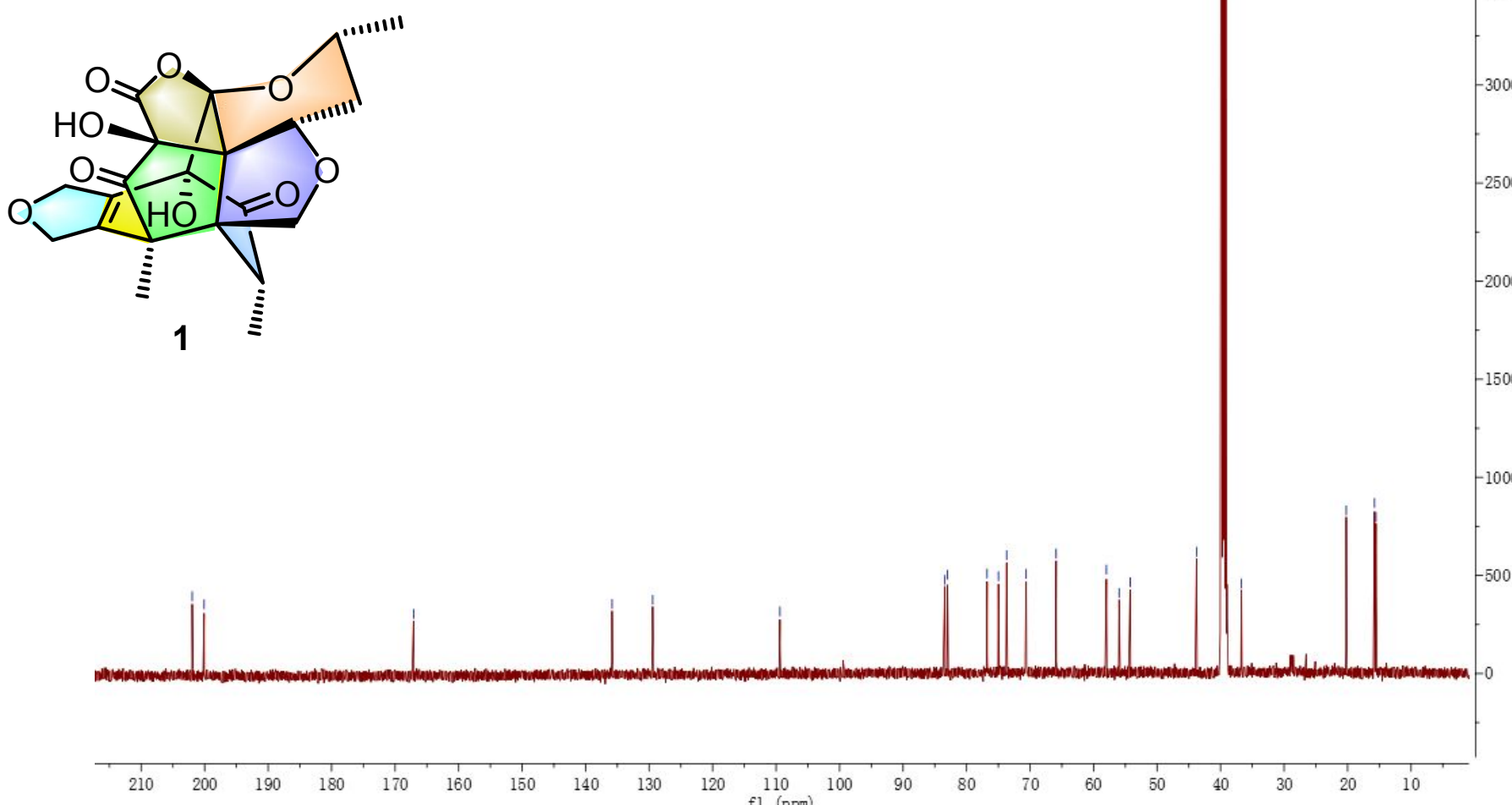

Figure S7. ${ }^{13} \mathrm{C}$ NMR spectrum (DMSO- $d_{6}, 125 \mathrm{MHz}$ ) of compound $\mathbf{1}$. 


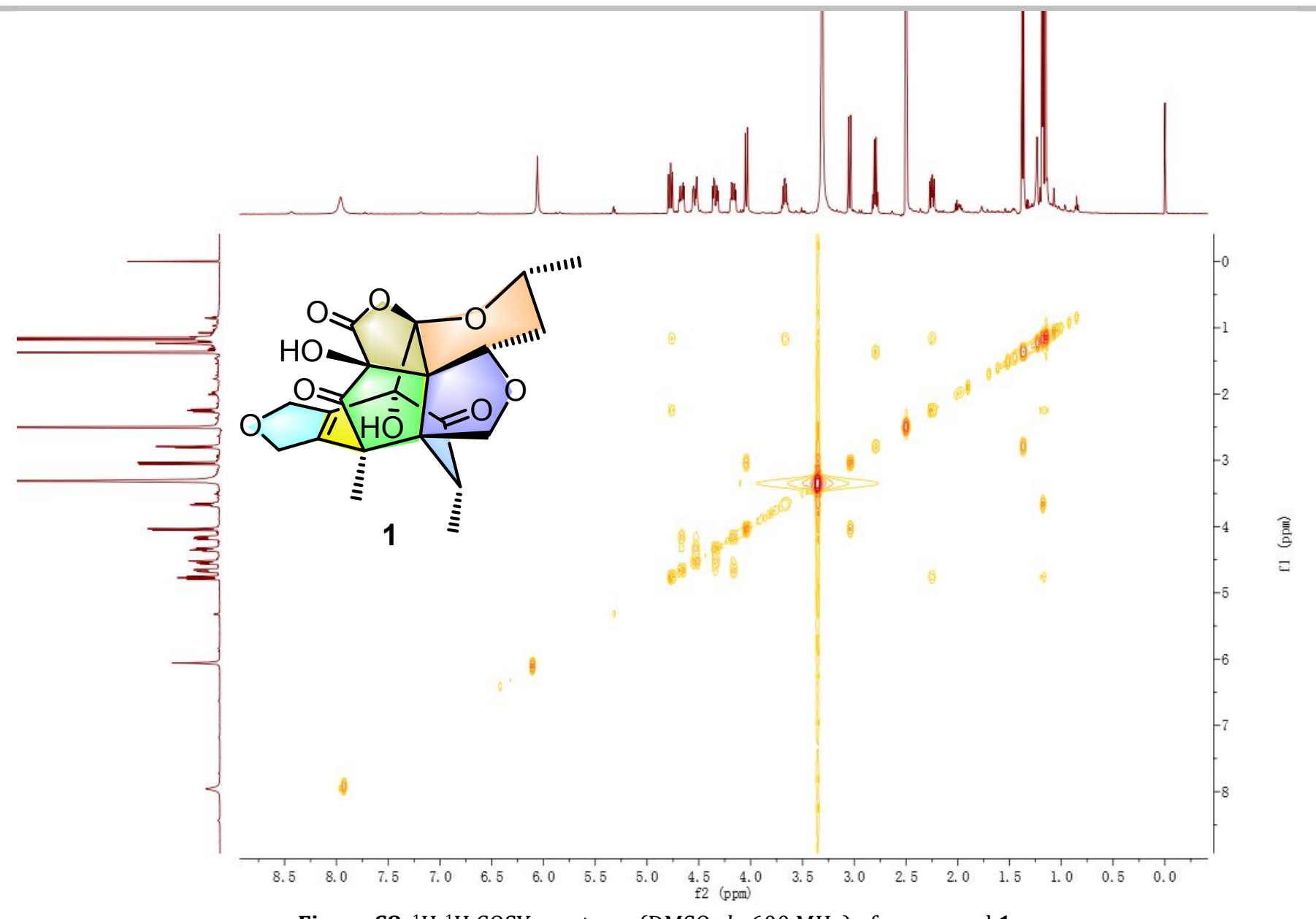

Figure S8. ${ }^{1} \mathrm{H}-{ }^{1} \mathrm{H}$ COSY spectrum (DMSO- $d_{6}, 600 \mathrm{MHz}$ ) of compound 1. 


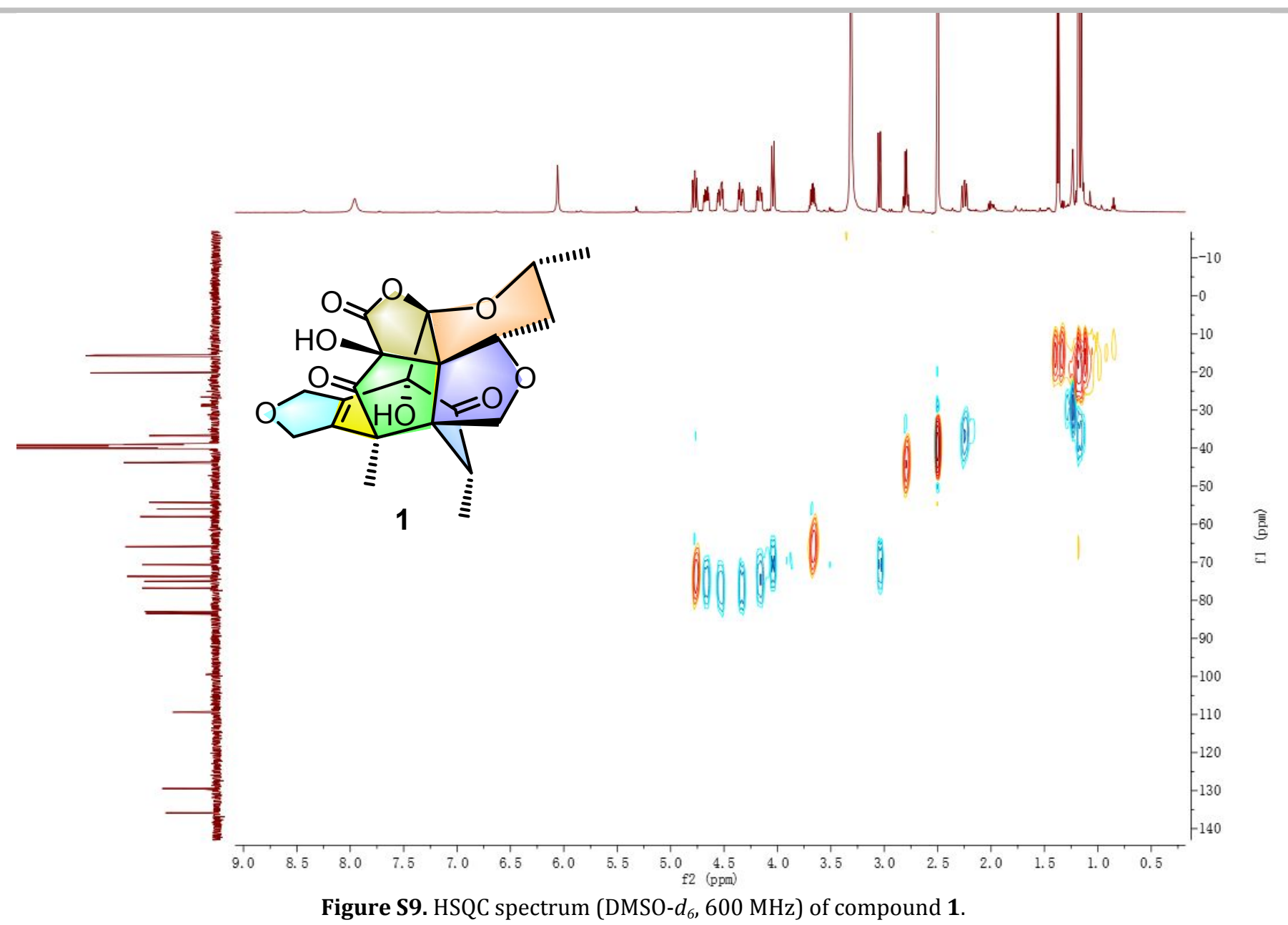




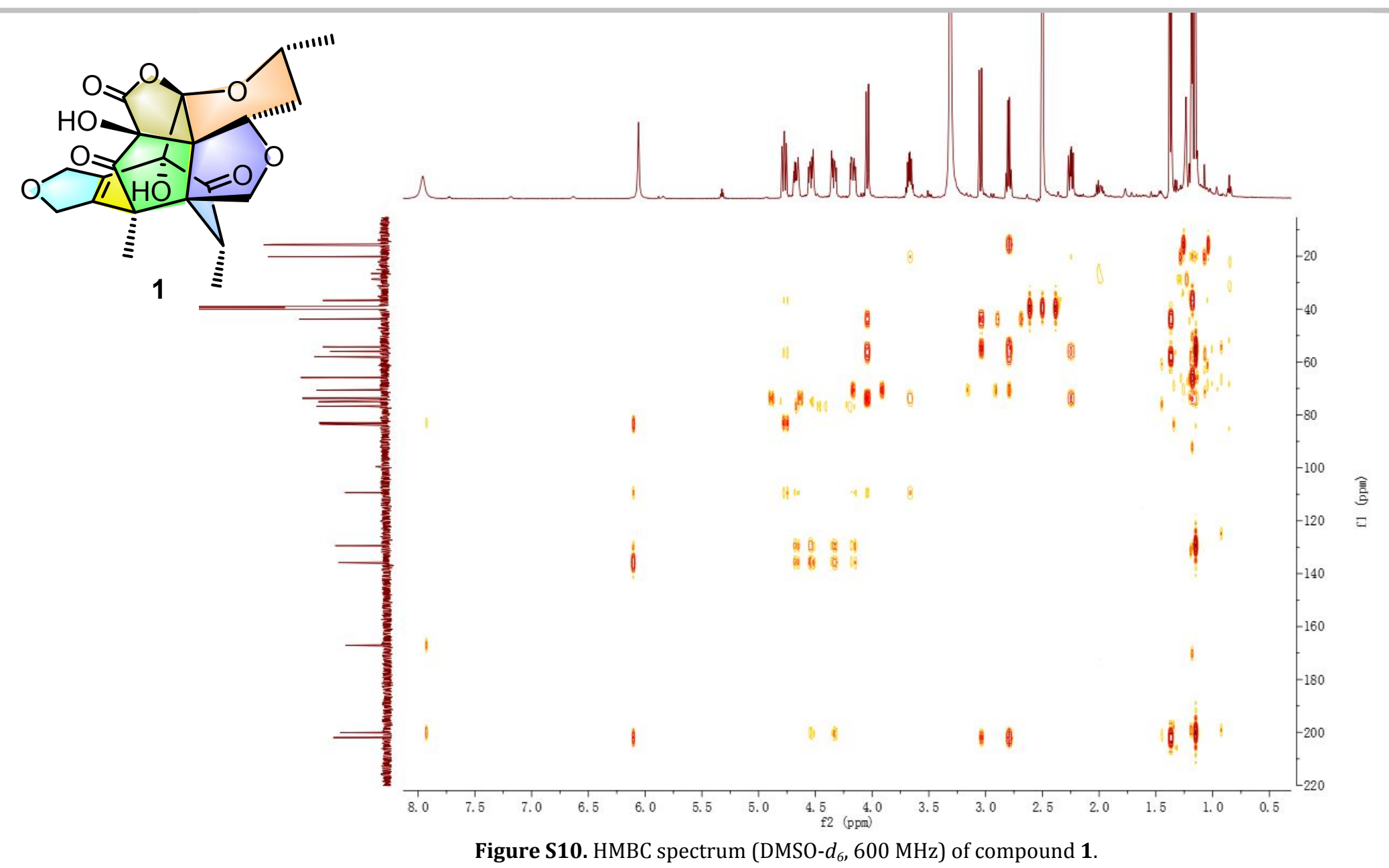




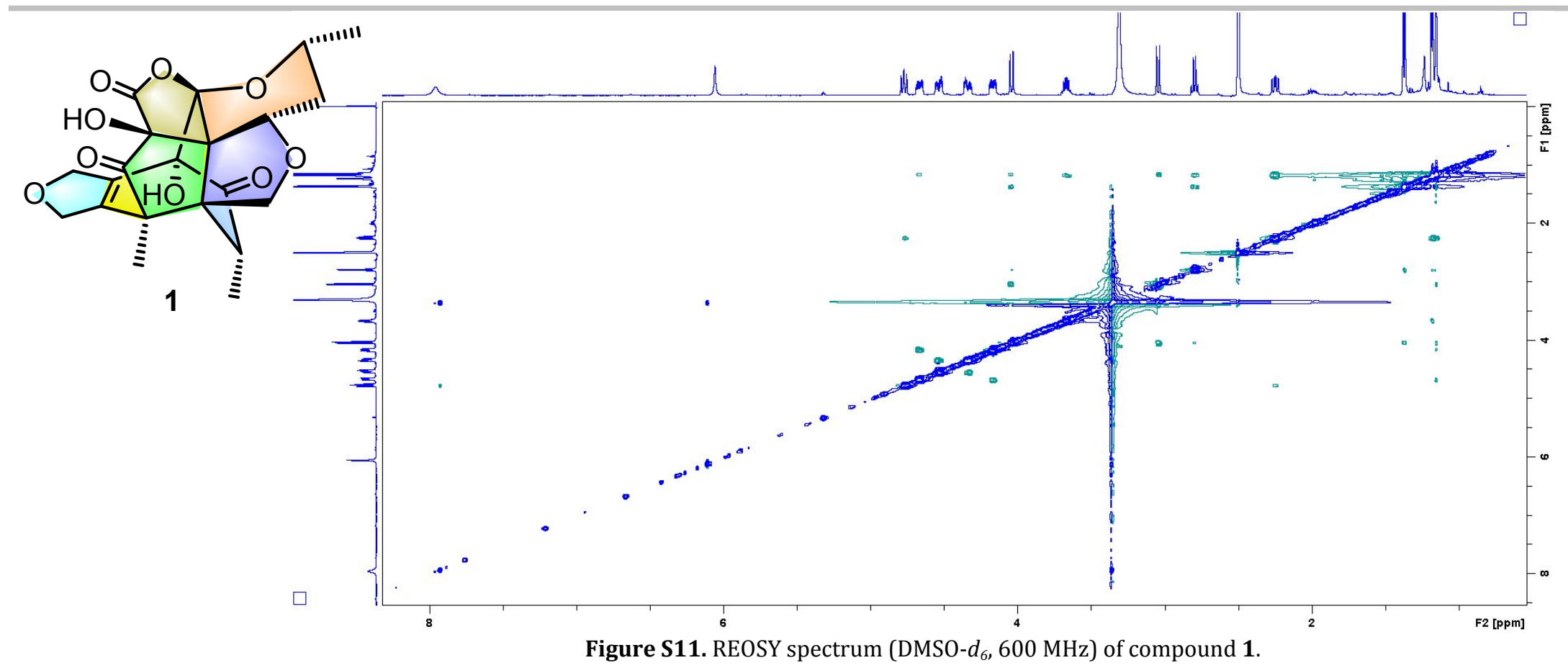




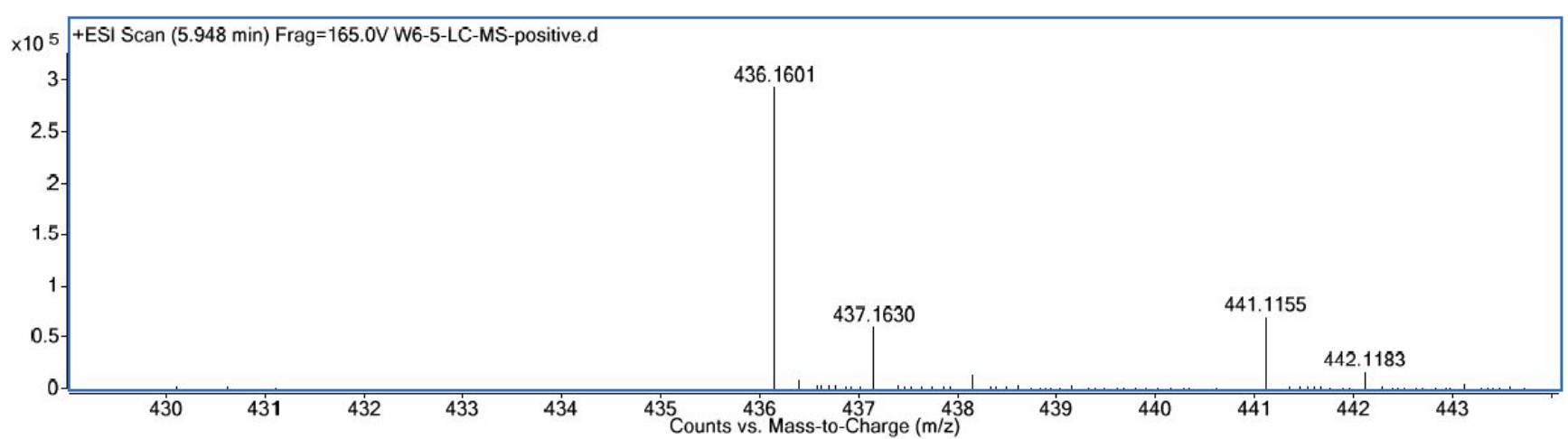

\section{Elemental Composition Calculator}

\begin{tabular}{|c|c|c|c|c|c|}
\hline Target $\mathrm{m} / \mathrm{z}$ : & 436.1601 & Result type: & Positive ions & Species: & {$[\mathrm{M}+\mathrm{NH} 4]^{+}$} \\
\hline \multicolumn{2}{|c|}{ Elements: } & \multicolumn{4}{|c|}{$\mathrm{C}(0-80) ; \mathrm{H}(0-120) ; \mathrm{O}(0-30) ; \mathrm{N}(0-10)$} \\
\hline \multicolumn{2}{|c|}{ Ion Formula } & \multicolumn{2}{|c|}{ Calcalated $\mathrm{m} / \mathrm{z}$} & \multicolumn{2}{|c|}{ PPM Error } \\
\hline \multicolumn{2}{|c|}{ C21H26NO9 } & \multicolumn{2}{|c|}{436.1602} & \multicolumn{2}{|c|}{0.17} \\
\hline
\end{tabular}

Figure S12. HRESIMS spectrum of compound 1. 


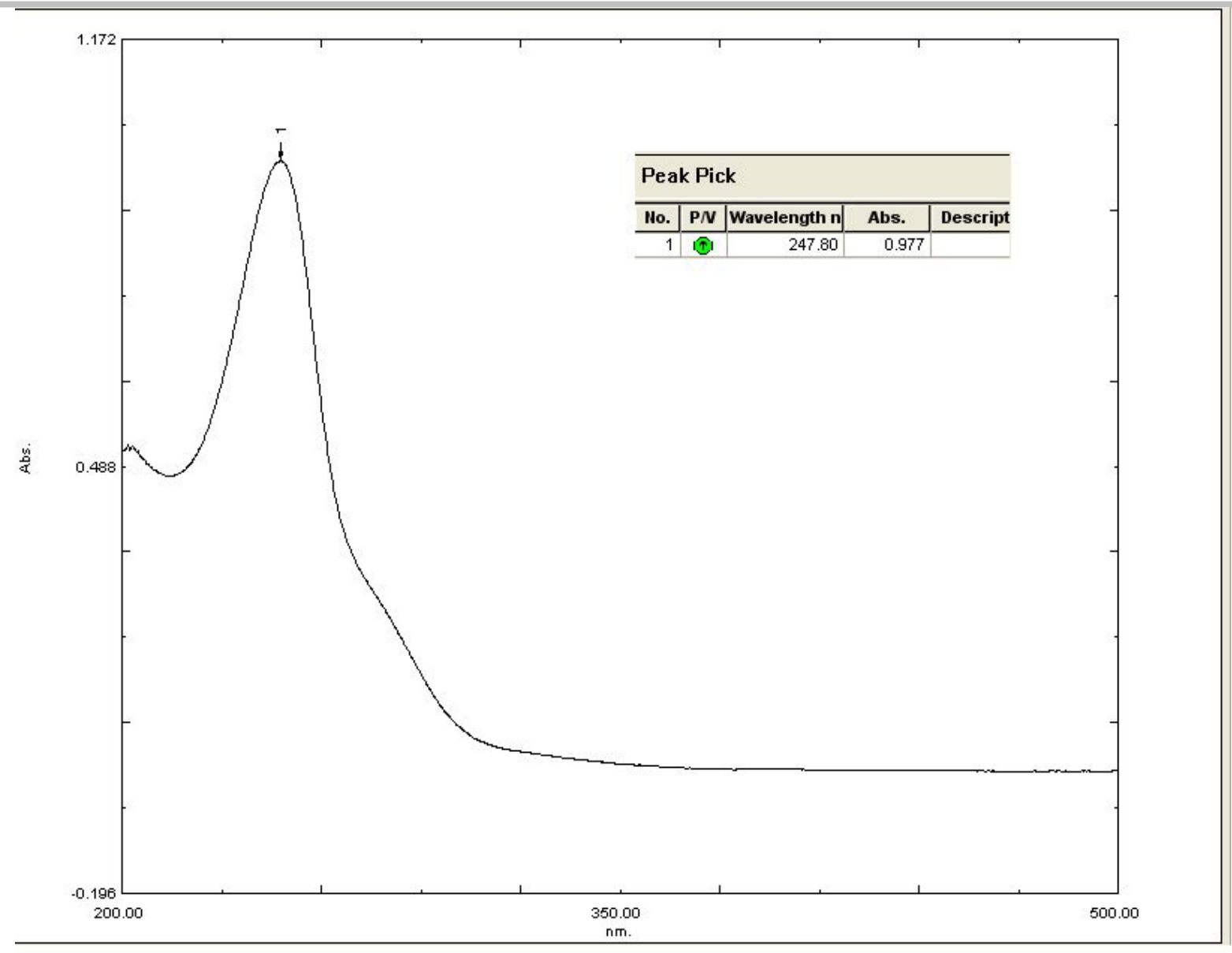

Figure S13. UV spectrum of compound 1. 


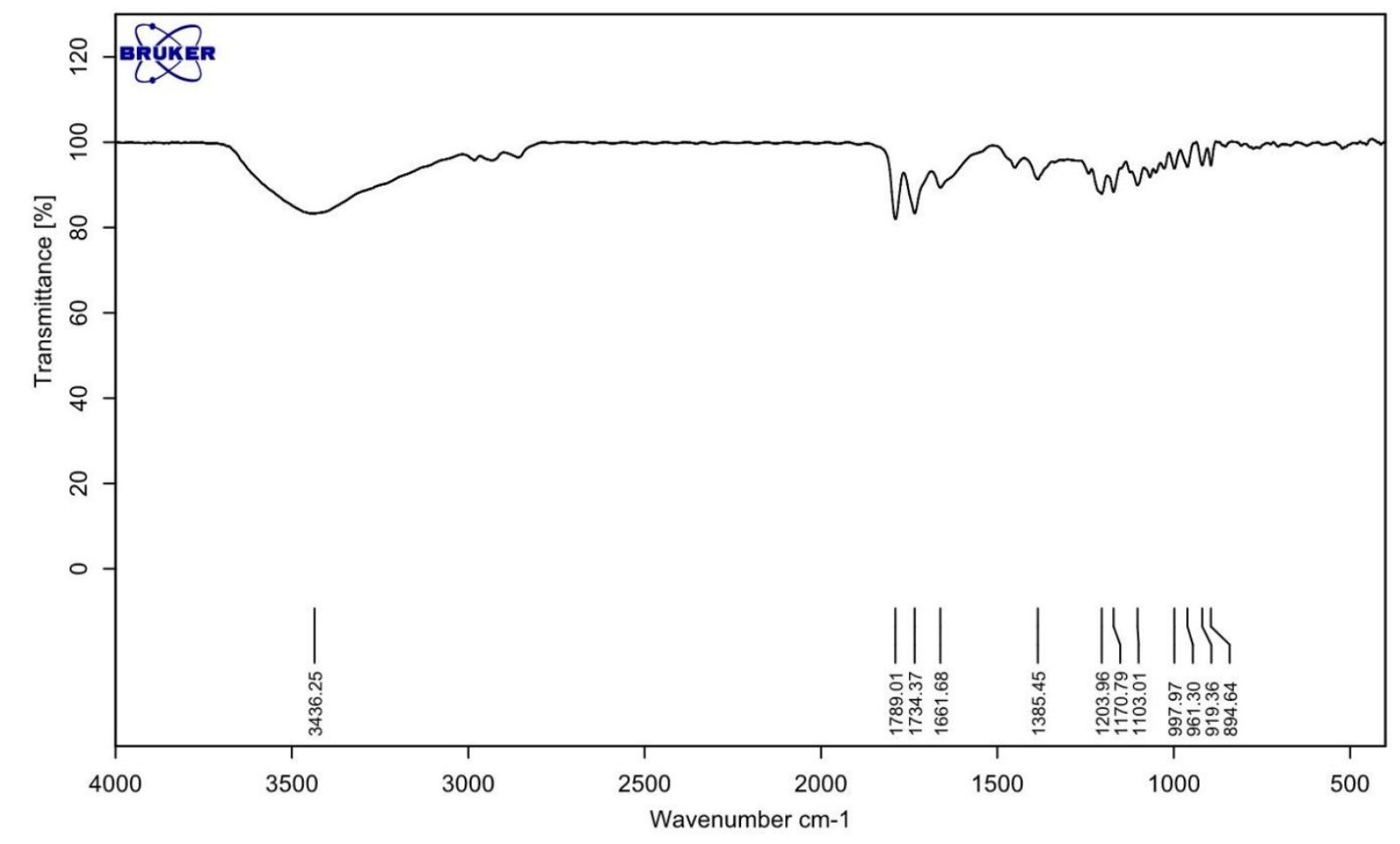

Figure S14. IR spectrum of compound 1. 
NMR, HRESIMS, UV, and IR spectra of compound 2

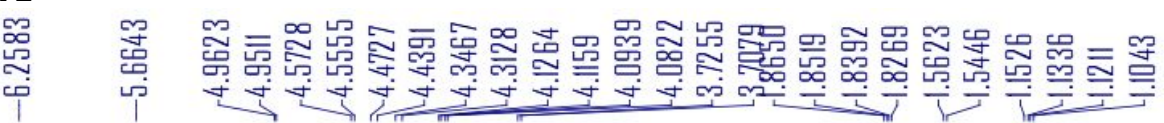

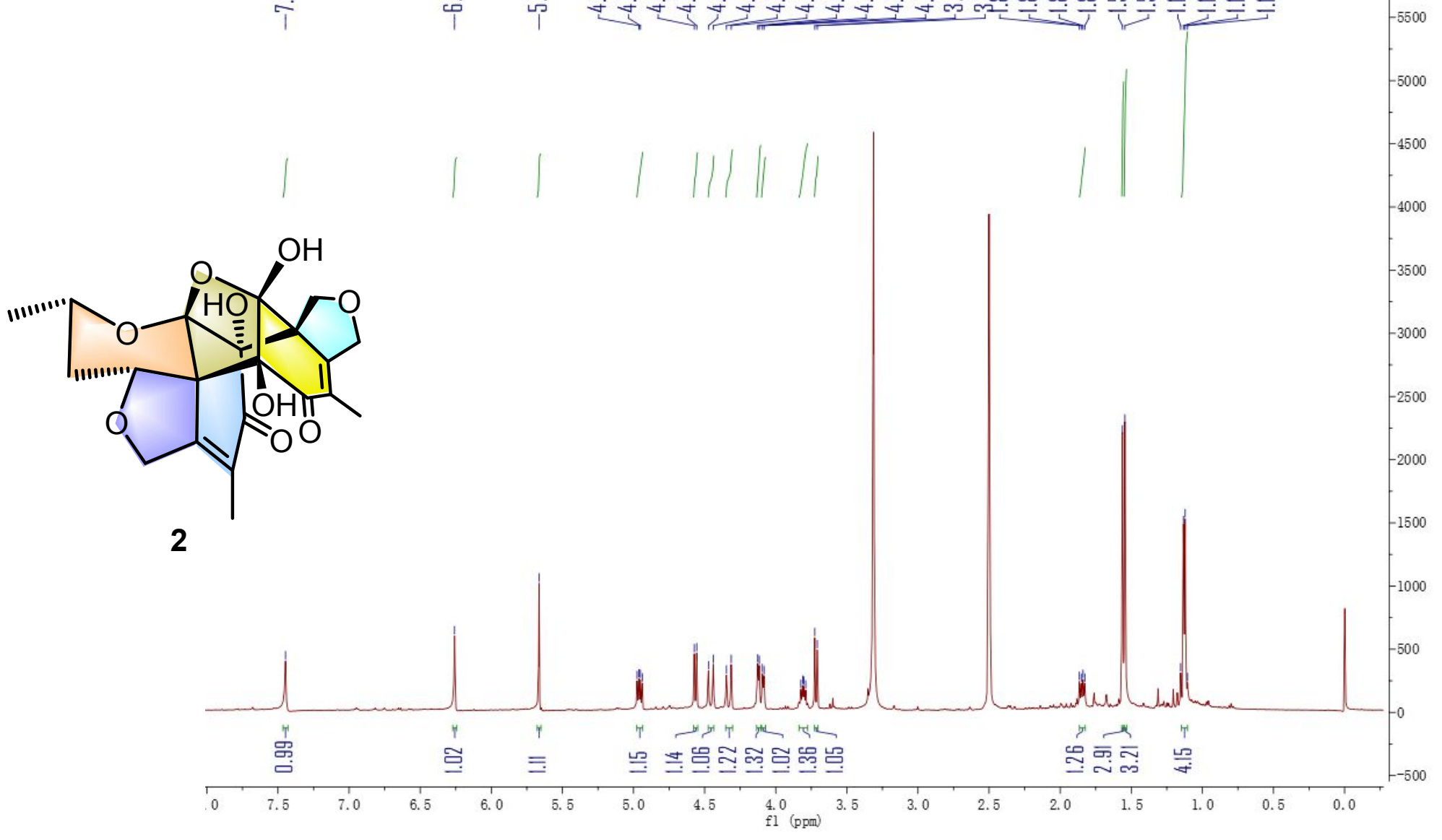

Figure S15. ${ }^{1} \mathrm{H}$ NMR spectrum (DMSO- $d_{6}, 500 \mathrm{MHz}$ ) of compound 2. 


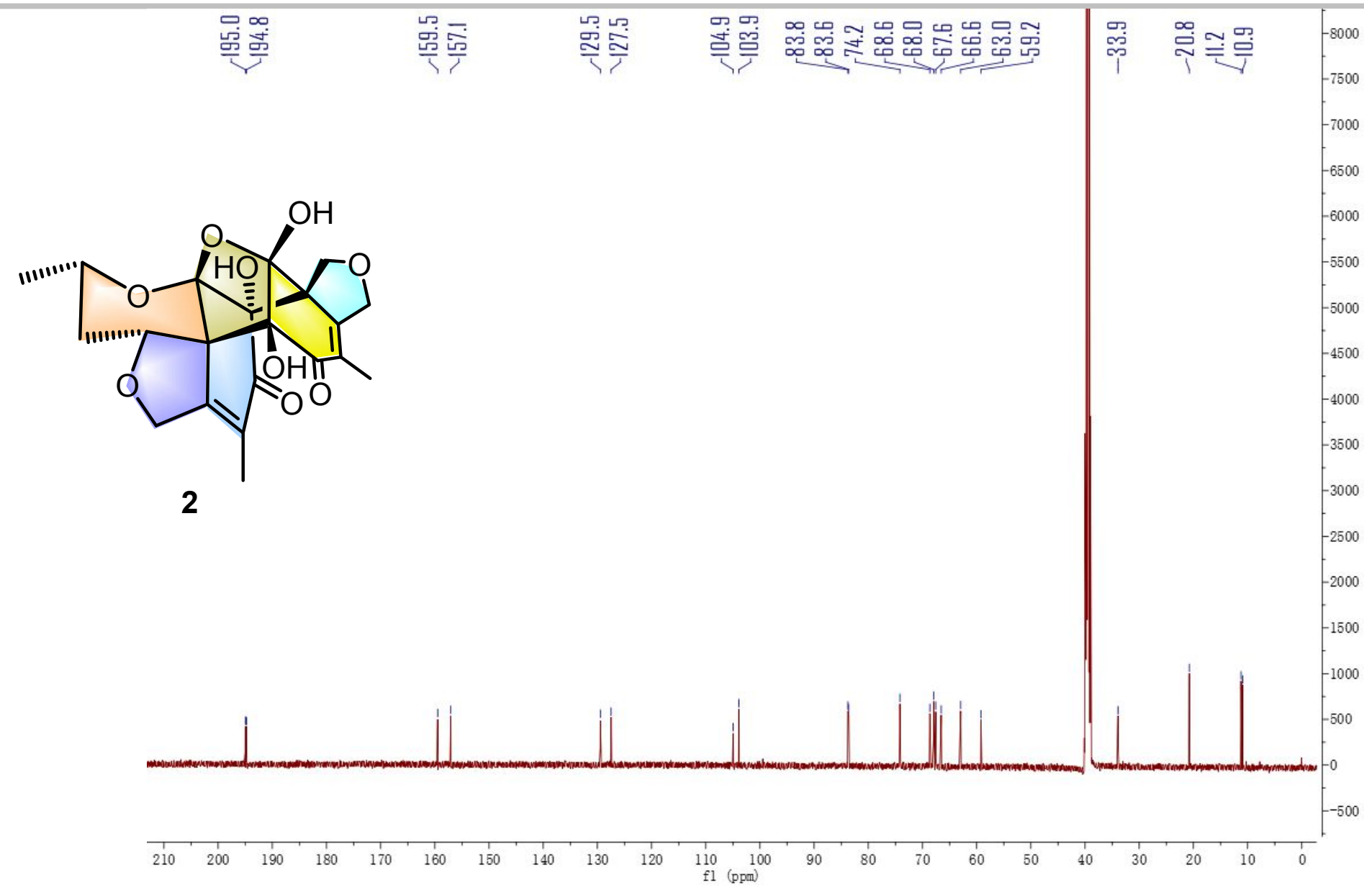

Figure S16. ${ }^{13} \mathrm{C}$ NMR spectrum (DMSO- $d_{6}, 125 \mathrm{MHz}$ ) of compound 2 . 


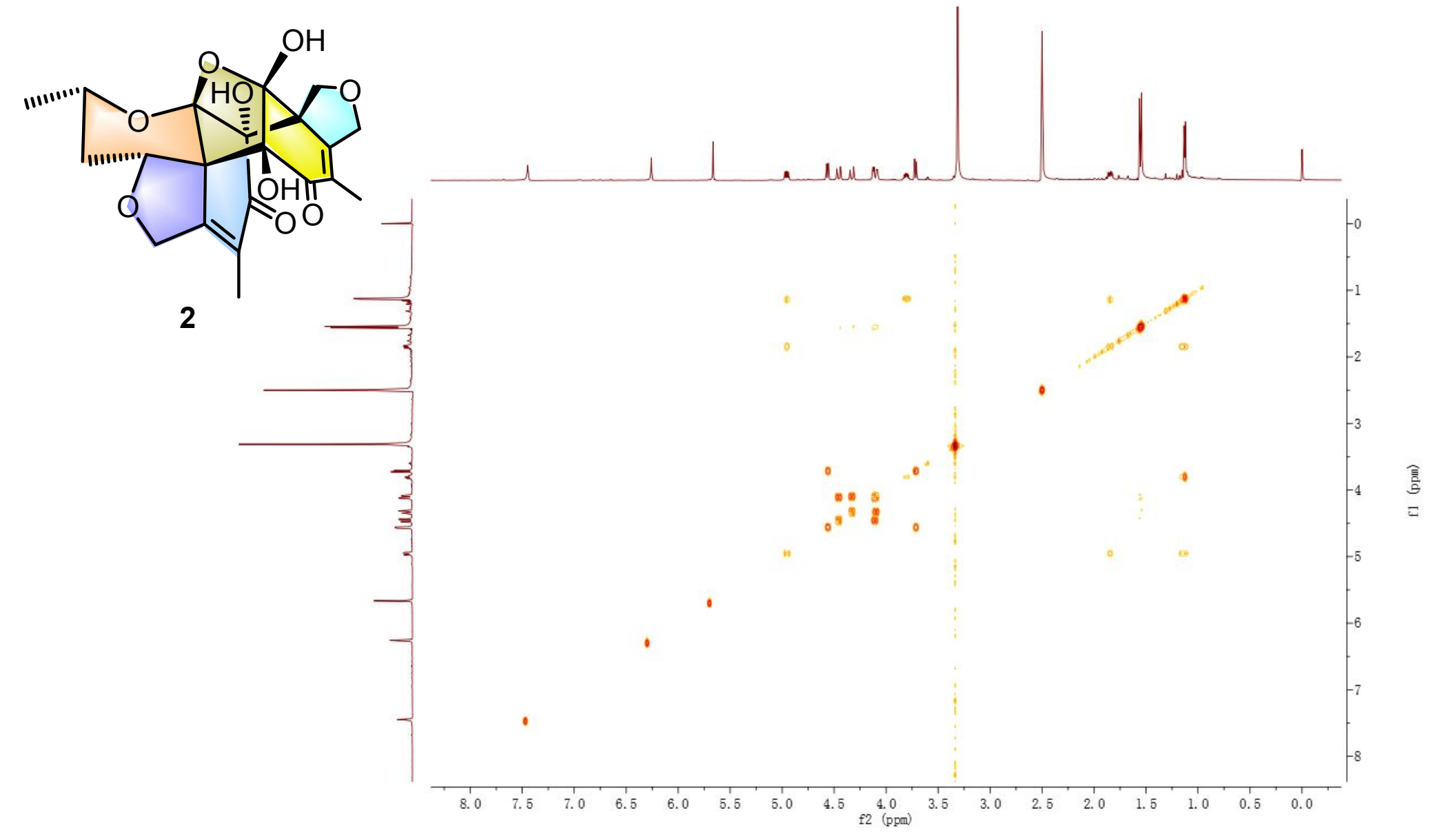

Figure S17. ${ }^{1} \mathrm{H}-1 \mathrm{H}$ COSY spectrum (DMSO- $d_{6}, 600 \mathrm{MHz}$ ) of compound 2. 


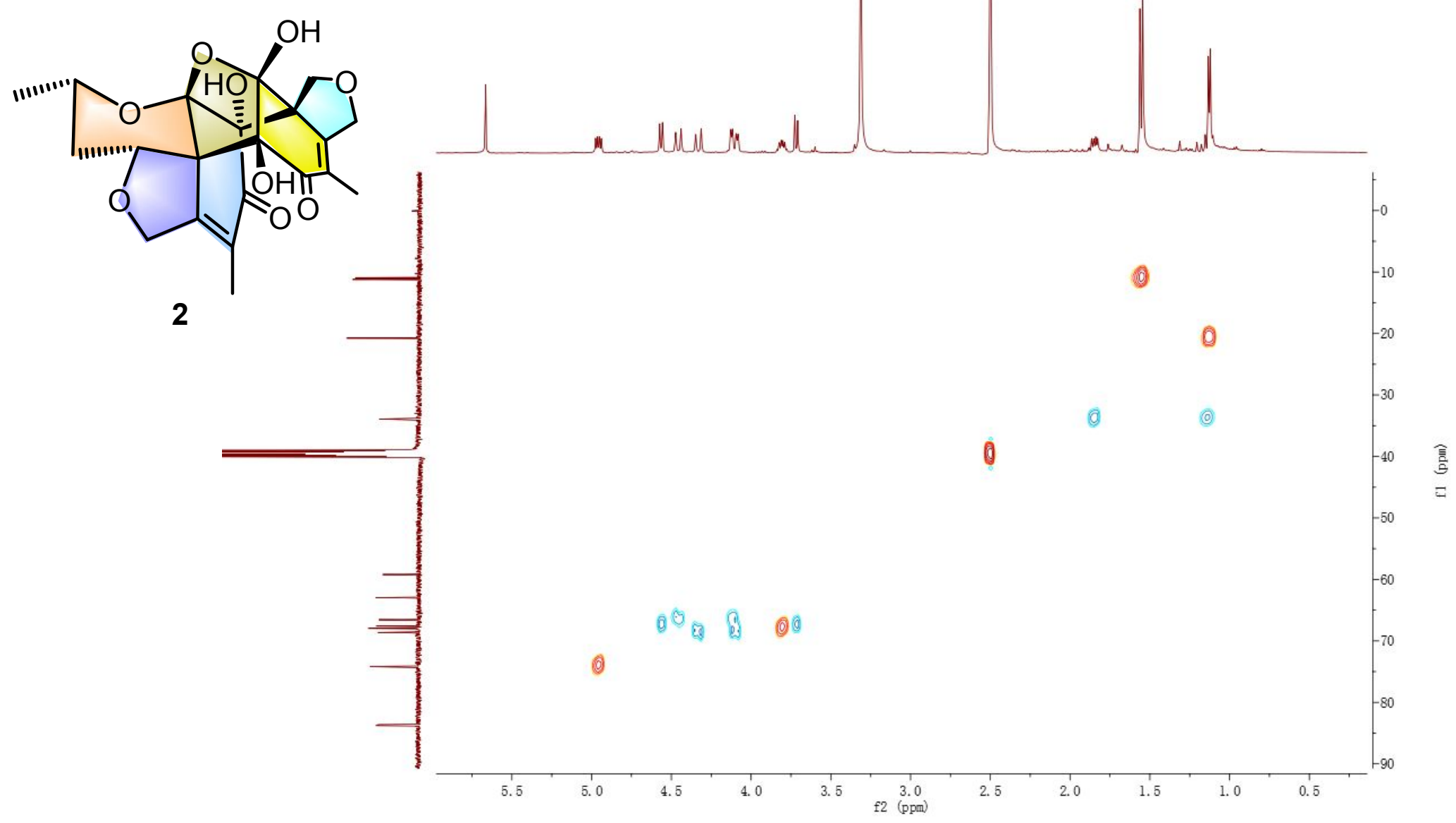

Figure S18. HSQC spectrum (DMSO- $d_{6}, 600 \mathrm{MHz}$ ) of compound 2. 


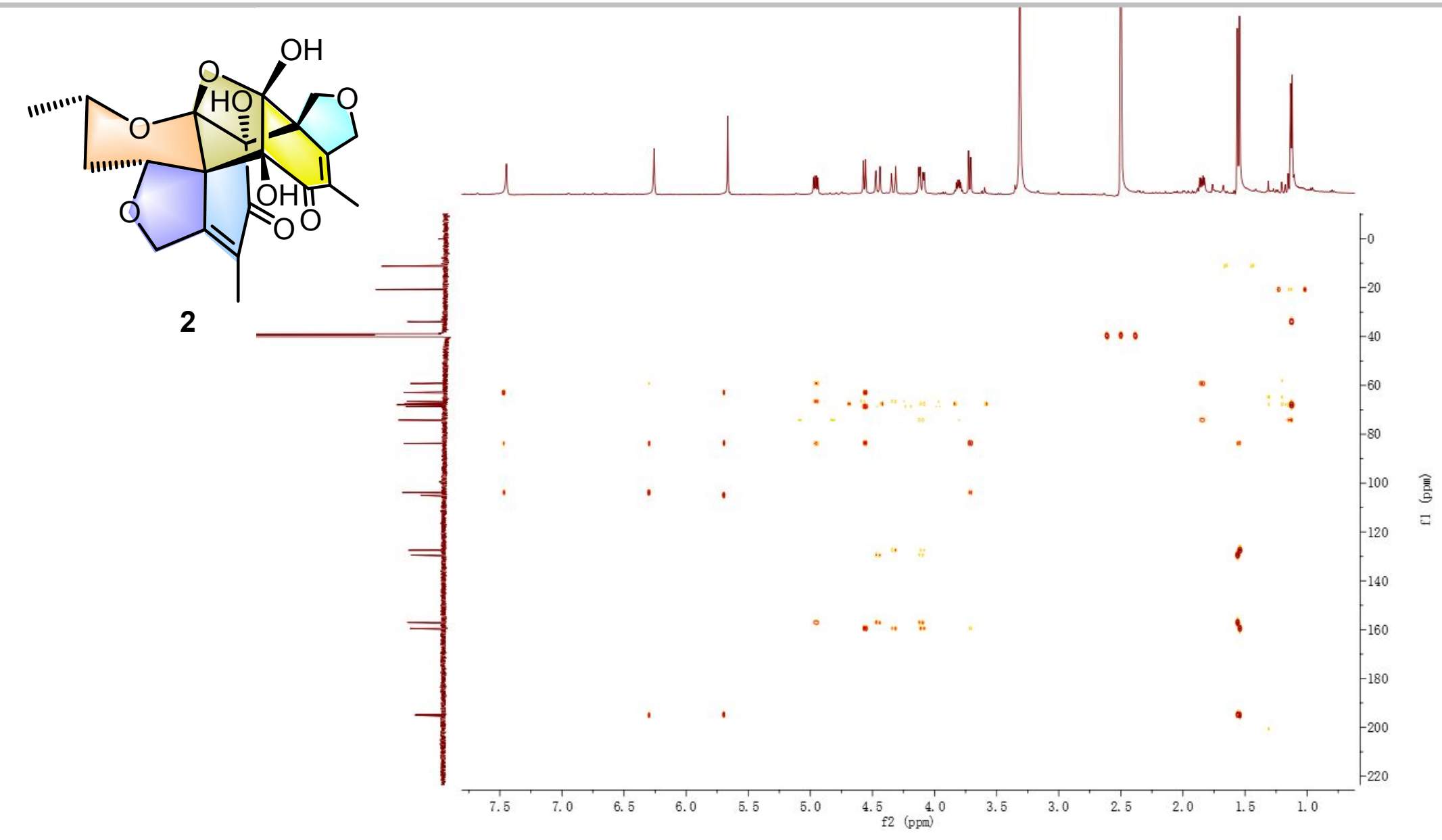

Figure S19. HMBC spectrum (DMSO- $d_{6}, 600 \mathrm{MHz}$ ) of compound 2. 


\section{SUPPORTING INFORMATION}

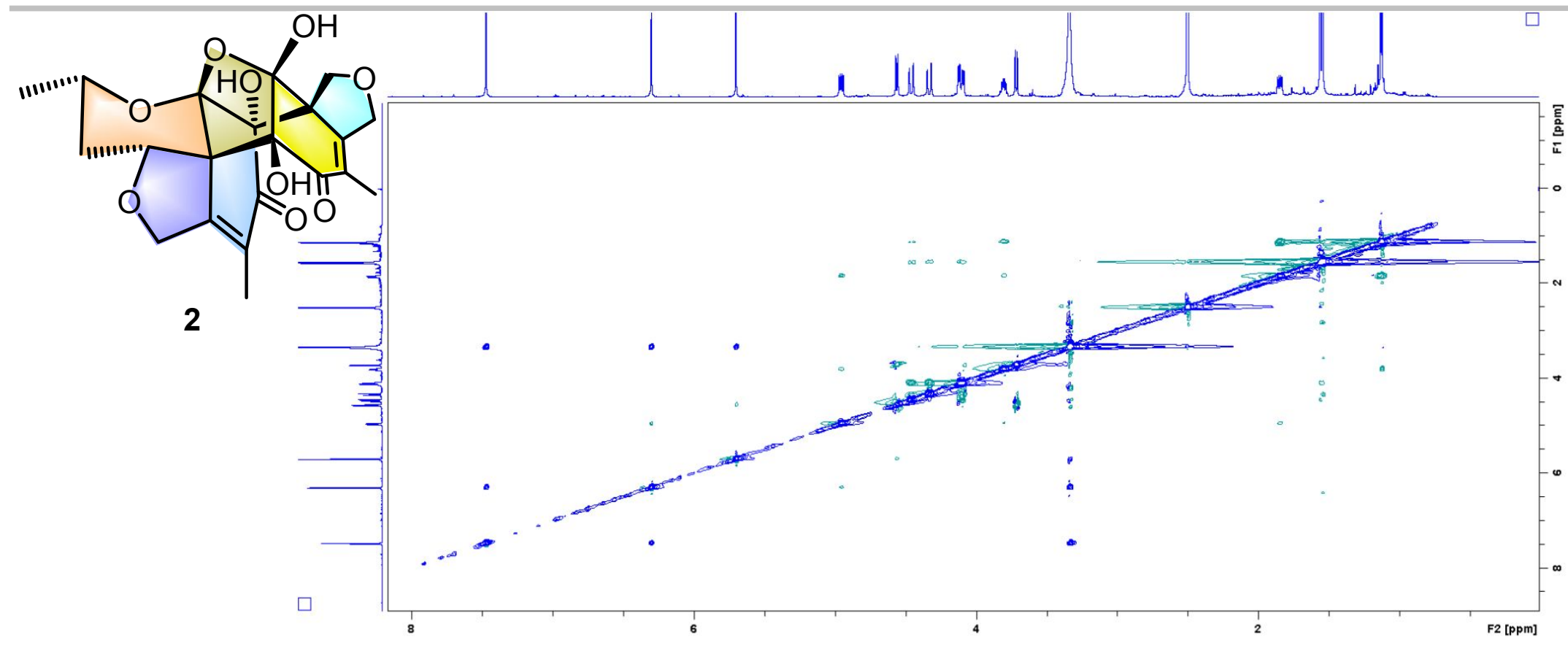

Figure S20. REOSY spectrum (DMSO- $d_{6}, 600 \mathrm{MHz}$ ) of compound 2. 


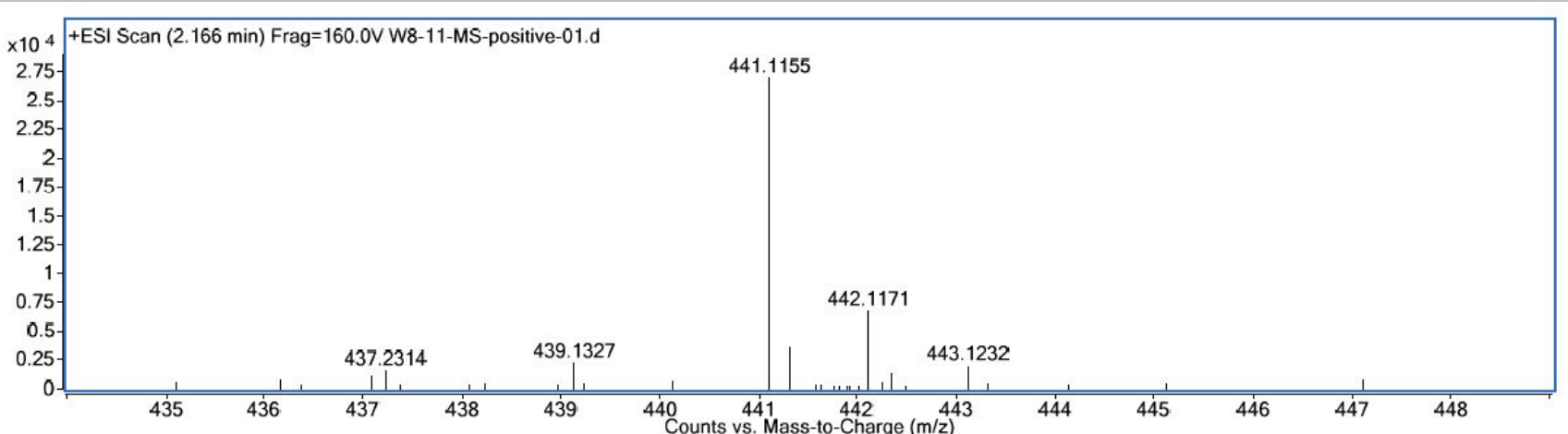

Elemental Composition Calculator

\begin{tabular}{|c|c|c|c|c|c|}
\hline Target $\mathbf{m} / \mathbf{z}$ : & 441.1155 & Result type: & Positive ions & Species: & {$[\mathrm{M}+\mathrm{Na}]^{+}$} \\
\hline \multicolumn{2}{|c|}{ Elements: } & \multicolumn{4}{|c|}{$\mathrm{C}(0-80) ; \mathrm{H}(0-120) ; \mathrm{O}(0-30) ; \mathrm{Na}(0-5)$} \\
\hline \multicolumn{2}{|c|}{ Ion Formula } & \multicolumn{2}{|c|}{ Calculated $\mathrm{m} / \mathrm{z}$} & \multicolumn{2}{|c|}{ PPM Error } \\
\hline \multicolumn{2}{|c|}{$\mathrm{C} 21 \mathrm{H} 22 \mathrm{NaO} 9$} & \multicolumn{2}{|c|}{441.1156} & \multicolumn{2}{|c|}{0.25} \\
\hline
\end{tabular}

Figure S21. HRESIMS spectrum of compound 2. 


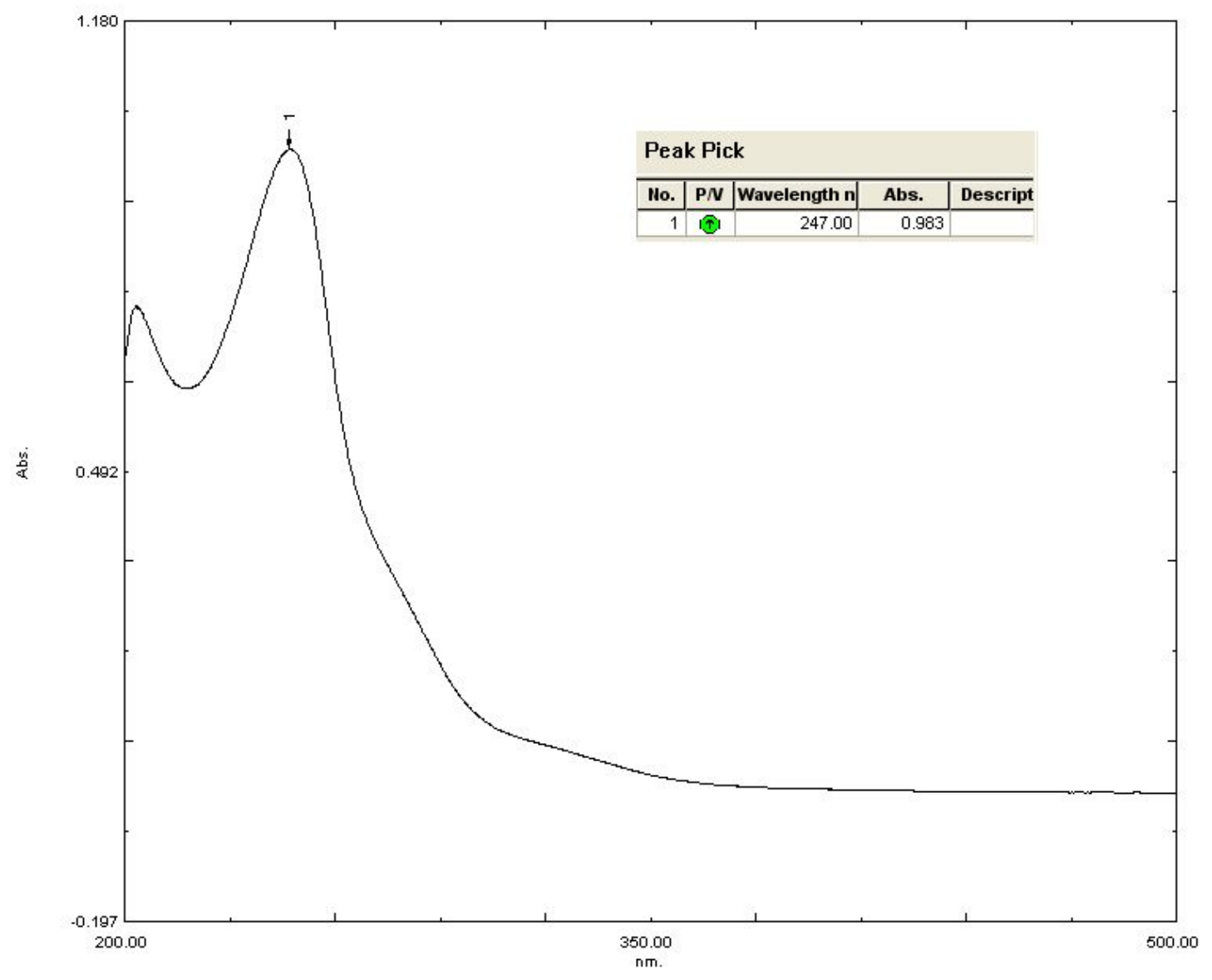

Figure S22. UV spectrum of compound 2. 


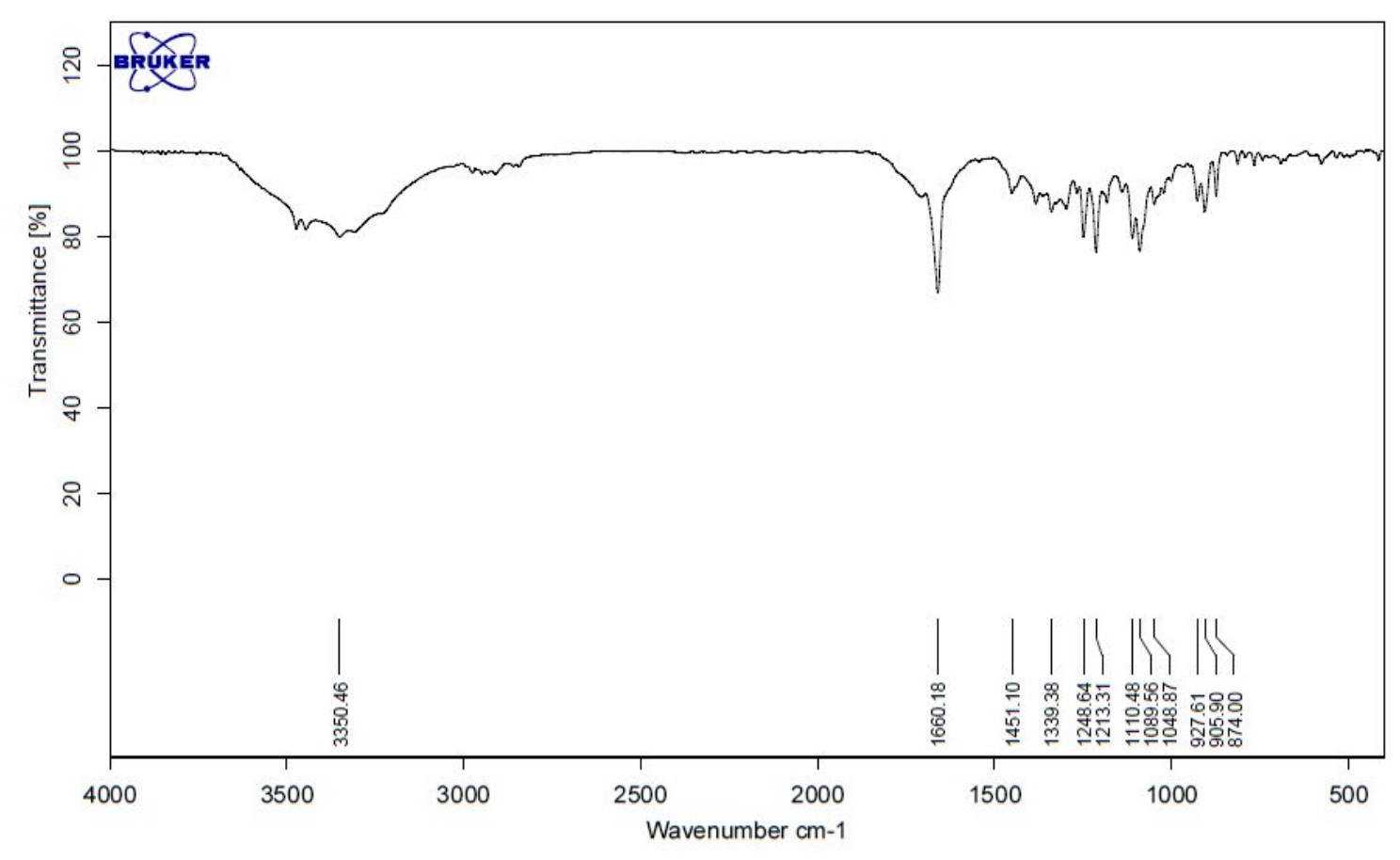

Figure S23. IR spectrum of compound 2. 